\title{
Current Treatment Options and Therapeutic Insights for Gastrointestinal Dysmotility and Functional Gastrointestinal Disorders
}

\section{OPEN ACCESS}

Edited by:

Ralf Weiskirchen,

RWTH Aachen University, Germany

Reviewed by:

Gregory Sayuk,

Washington University School of Medicine in St. Louis, United States

Jolien Schol,

Katholieke University Leuven, Belgium

*Correspondence:

Uday C Ghoshal

udayghoshal@gmail.com

Seungil Ro

sro@med.unr.edu

${ }^{\text {t}}$ These authors have contributed equally to this work

Specialty section: This article was submitted to Gastrointestinal and Hepatic Pharmacology,

a section of the journal

Frontiers in Pharmacology

Received: 03 November 2021 Accepted: 04 January 2022 Published: 25 January 2022

Citation:

Singh R, Zogg $H$, Ghoshal UC and

Ro $S$ (2022) Current Treatment Options and Therapeutic Insights for

Gastrointestinal Dysmotility and Functional Gastrointestinal Disorders.

Front. Pharmacol. 13:808195.

doi: 10.3389/fphar.2022.808195

\author{
Rajan Singh ${ }^{t, 1}$, Hannah Zogg ${ }^{t, 1}$, Uday C Ghoshal ${ }^{\star, 2}$ and Seungil Ro ${ }^{* 1}$ \\ ${ }^{1}$ Department of Physiology and Cell Biology, Reno School of Medicine, University of Nevada, Reno, NV, United States, \\ ${ }^{2}$ Department of Gastroenterology, Sanjay Gandhi Postgraduate Institute of Medical Sciences, Lucknow, India
}

Functional gastrointestinal disorders (FGIDs) have been re-named as disorders of gut-brain interactions. These conditions are not only common in clinical practice, but also in the community. In reference to the Rome IV criteria, the most common FGIDs, include functional dyspepsia (FD) and irritable bowel syndrome (IBS). Additionally, there is substantial overlap of these disorders and other specific gastrointestinal motility disorders, such as gastroparesis. These disorders are heterogeneous and are intertwined with several proposed pathophysiological mechanisms, such as altered gut motility, intestinal barrier dysfunction, gut immune dysfunction, visceral hypersensitivity, altered Gl secretion, presence and degree of bile acid malabsorption, microbial dysbiosis, and alterations to the gut-brain axis. The treatment options currently available include lifestyle modifications, dietary and gut microbiota manipulation interventions including fecal microbiota transplantation, prokinetics, antispasmodics, laxatives, and centrally and peripherally acting neuromodulators. However, treatment that targets the pathophysiological mechanisms underlying the symptoms are scanty. Pharmacological agents that are developed based on the cellular and molecular mechanisms underlying pathologies of these disorders might provide the best avenue for future pharmaceutical development. The currently available therapies lack long-term effectiveness and safety for their use to treat motility disorders and FGIDs. Furthermore, the fundamental challenges in treating these disorders should be defined; for instance, 1. Cause and effect cannot be disentangled between symptoms and pathophysiological mechanisms due to current therapies that entail the off-label use of medications to treat symptoms. 2. Despite the knowledge that the microbiota in our gut plays an essential part in maintaining gut health, their exact functions in gut homeostasis are still unclear. What constitutes a healthy microbiome and further, the precise definition of gut microbial dysbiosis is lacking. More comprehensive, large-scale, and longitudinal studies utilizing multi-omics data are needed to dissect the exact contribution of gut microbial alterations in disease pathogenesis. Accordingly, we review the current treatment options, clinical insight on pathophysiology, therapeutic modalities, current challenges, and therapeutic clues for the clinical care and management of functional dyspepsia, gastroparesis, irritable bowel syndrome, functional constipation, and functional diarrhea.

Keywords: gastroparesis, functional dyspepsia, irritable bowel syndrome, visceral hypersensitivity, impaired barrier function, prucalopride, relamorelin, fecal microbiota transplantation 


\section{INTRODUCTION}

Functional gastrointestinal disorders (FGIDs) have been described as disorders of gut-brain interactions and are not only common in clinical practice, but also in the community (Black et al., 2020b; Sperber et al., 2021a). Recently, it has been estimated that the prevalence of FGIDs worldwide is $40 \%$ based on Rome IV criteria (Sperber et al., 2021b). However, of the 22 FGIDs as per Rome IV criteria, only a few are very common. In reference to the Rome IV criteria, the most common FGIDs are functional dyspepsia (FD) and irritable bowel syndrome (IBS) (Sperber et al., 2021a). Rome IV criteria defines FD as the presence of one or more upper abdominal symptoms: epigastric pain, epigastric burning, postprandial fullness, and early satiation and symptoms should have been active in the past 3 months, with onset at least 6 months before diagnosis; however, there should be no signs of structural disease (evaluated using upper endoscopy) that could account for these symptoms (Drossman, 2016). Additionally, FD has been divided into two sub-groups: epigastric pain syndrome (EPS) and postprandial distress syndrome (PDS) (Drossman, 2016). When symptoms (epigastric pain and burning) arise with no correlation to meal timing, it is classified as EPS, whereas when symptoms (epigastric pain, early satiation and postprandial fullness) arise or are aggravated following a meal, it is classified as PDS. Notably, there is substantial overlap between EPS and PDS subgroups. Further, as per the Rome IV criteria, IBS has been defined as altered stool frequency or form associated with abdominal pain and has occurred for a minimum of 6 months (Drossman, 2016). Further subdivision of patients occurs based on the main stool form observed using the Bristol Stool Form Scale: constipationpredominant IBS (IBS-C), diarrhea-predominant IBS (IBS-D), IBS with a mixture of stool patterns (IBS-M), and IBS with the stool pattern unclassified (IBS-U) (Drossman, 2016).

Additionally, there is substantial co-occurrence of FD and IBS (Ghoshal and Singh, 2017; Black and Ford, 2020; Ghoshal, 2020; Sperber et al., 2021b). Also, some specific GI motility disorders overlap with FD and IBS; for instance, gastroparesis overlaps with FD-PDS, similarly functional constipation has significant overlap with IBS-C and functional diarrhea with IBS-D (Parkman et al., 2011; Zikos et al., 2019). Gastroparesis is characterized by upper GI symptoms, including early satiety, vomiting, bloating, nausea, upper abdominal pain, postprandial fullness, along with delayed gastric emptying of solids without any mechanical obstruction (Grover et al., 2019; Camilleri and Sanders, 2021). Functional constipation is comprised within the clinical spectrum of IBS-C, and defecatory disorders and can be caused by colonic myopathies or motor disorders, which typically correlate with low-amplitude contractions that result in colonic stasis and impaired propulsion (Sharma et al., 2021). These altered colonic functions increase the reabsorption of water and hardening of stool, which is typically associated with a reduction in the sensation of the need to defecate. Moreover, gut motility disorders are often mistaken as FGIDs due to the subtle symptoms and the clinical and pathophysiological features it presents with.

GI motility disorders and FGIDs are diverse in nature and are intertwined with multiple pathophysiological mechanisms, such as altered gut dysmotility, intestinal barrier dysfunction, gut immune dysfunction, visceral hypersensitivity, altered GI secretion, presence and degree of bile acid (BA) malabsorption, gut microbiota dysbiosis, and altered gut-brain axis (Ghoshal and Singh, 2014; Enck et al., 2016; Enck et al., 2017; Camilleri et al., 2018; Grover et al., 2019). In these disorders, delayed or accelerated GI transit is associated with abnormal gut muscular movements (Shin et al., 2019; Singh et al., 2021b). IBS-C and functional constipation patients often have delayed GI transit, while IBS-D and functional diarrhea have accelerated GI transit (Shin et al., 2019). The underlying mechanism behind the development of FD-EPS and IBS-D is proposed to be visceral hypersensitivity while impaired fundus accommodation and delayed gastric emptying are the underlying mechanisms for FD-PDS and gastroparesis (Enck et al., 2017; Masuy et al., 2019b). Gut microbial dysbiosis leads to the activation of the gut immune response and causes epithelial barrier dysfunction, which then induces gut dysmotility and visceral hypersensitivity (Barbara et al., 2016b; Singh et al., 2021d). These findings reinforce the idea of impaired intestinal barrier function being a core pathophysiological mechanism behind FGIDs. Further, psychological comorbidities, including anxiety, depression, and stress, are often correlated with FGIDs and likely contribute to the altered pathophysiology of gut-brain interactions (Ghoshal, 2020). Understanding cellular and molecular mechanisms of underlying pathogenesis behind the gut motility disorders and FGIDs has substantially evolved during recent years. Synchronization of the enteric, parasympathetic, and sympathetic nervous system is necessary for normal control of gut function, which relies on specific GI cell types such as enteric neurons, immune cells (resident macrophages and mast cells), interstitial cells of Cajal (ICCs), enteroendocrine cells, and smooth muscle cells (SMCs) (Sanders et al., 2012; Yoo and Mazmanian, 2017). Through established animal models and human studies, the functional defects in these cells have been evidenced in the pathogenesis of these disorders (Cipriani et al., 2016; Grover et al., 2019; Mazzone et al., 2020; Singh et al., 2021a; Wei et al., 2021a). Further, these studies energized a new treatment paradigm with pharmacological agents targeting cellular and molecular defects seen in these disorders.

The treatment of FGIDs and gut motility disorders has undergone a substantial paradigm shift in recent years from symptomatic treatment to subtyping of the condition and the underlying pathophysiology. Prokinetics, antispasmodics, centrally acting neuromodulators, fecal microbiota transplantation (FMT), and modified lifestyle (dietary, probiotic, and/or antibiotic interventions), are currently available treatment options for these disorders. Current proposed pharmacological agents modulating pathophysiological mechanisms include prokinetic agents (5HT4R agonists, 5-HT3R antagonists, 5-HT1AR agonists, ghrelin receptor agonists, dopamine-2 receptor antagonists, and muscarinic receptor antagonists) for altered gut motility, mast cell stabilizer for gut immune dysfunction, acid suppression therapy and histamine receptor-1 (HRH1) antagonists for impaired duodenal clearance of gastric acid and visceral hypersensitivity, $\mu$-Opioid receptor $(\mu$-OR) ligands and 


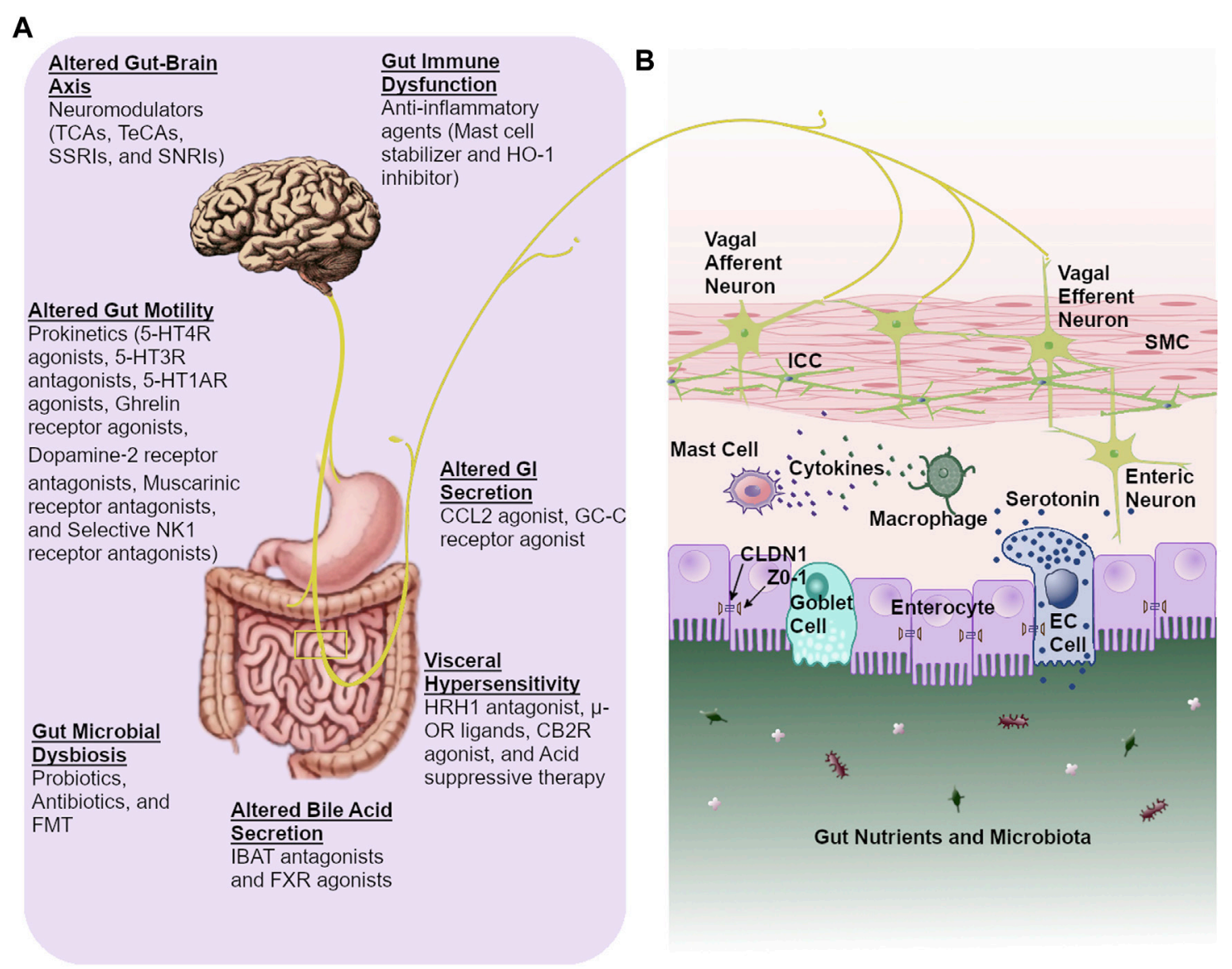

FIGURE 1 | Pathophysiology-directed therapeutic approach for gastrointestinal dysmotility and functional gastrointestinal disorders. (A). Currently available pharmacological agents based on pathophysiological mechanisms (B). Proper gut functioning relies on a coordinated communication between intestinal epithelial cells, enteric neurons, gastrointestinal pacemaking cells, and immune cells. This allows for essential crosstalk between the gut microbiota, gut, and brain. Abbreviations: CCL2: chloride channel 2, CB2R: cannabinoid type 2 receptor, CLDN1: claudin 1, TCAs: tricyclic anti-depressants, TeCAs: tetracyclic anti-depressants, SSRIs: selective serotonin reuptake inhibitors, IBAT: ileal bile acid transporter, HO-1: heme oxygenase-1, 5-HT1AR: serotonin 1A receptor, NK1: neurokinin 1, FMT: fecal microbiota transplantation, FXR: farnesoid X receptor, $\mathrm{HRH1}$ : histamine receptor-1, $\mu$-OR: $\mu$-opioid receptor, GC-C: guanylate cyclase-C, ICC: interstitial cells of Cajal, EC: enterochromaffin, ZO-1: zonula occludens-1, SNRIs: serotonin noradrenaline reuptake inhibitors, SMC: smooth muscle cell.

cannabinoid type 2 receptor (CB2R) agonist for visceral pain, chloride channel 2 (CCL2) and guanylate cyclase-C (GC-C) receptor agonists for altered GI secretion, farnesoid $\mathrm{X}$ receptor (FXR) agonist and ileal bile acid transporter (IBAT) antagonist for altered BA secretion, central and visceral neuromodulators [tricyclic anti-depressant (TCA), tetracyclic anti-depressants (TeCA), serotonin noradrenaline reuptake inhibitors (SNRIs), and selective serotonin reuptake inhibitors (SSRIs)] for altered gut-brain axis (Drossman et al., 2018; Simren and Tack, 2018; Grover et al., 2019; Masuy et al., 2019b; Black et al., 2020b; Ghoshal, 2020; Camilleri, 2021; Sharma et al., 2021) (Figure 1). However, it is of utmost importance to unearth alternative treatment options that target the pathophysiological mechanisms underlying these conditions. Furthermore, the cause and effect cannot be disentangled among symptoms and underlying pathophysiological mechanisms due to the fact that current therapies entail the off-label use of medications to treat symptoms. More comprehensive, large-scale, and longitudinal studies utilizing multi-omics data are needed to elucidate the exact contributors in disease pathogenesis, particularly those that could be actionable with pharmacologic agents. However, it should be noted that the general lack of biomarkers, both in diagnosing FGIDs as well as for use as predictors of the patient's response to specific treatment strategies, will likely cause further challenges for the use of "multi-omics" based longitudinal studies. Owing to the fact that a majority of current treatment options are based on symptomology, pathophysiology-based treatment might serve as a more beneficial foundation for future treatments of motility disorders and FGIDs. Accordingly, this review aims to deliberate the clinical insight on pathophysiology-directed therapeutic modalities, current challenges, and therapeutic clues, while emphasizing current gaps in knowledge as well as future directions for enhanced clinical care of motility disorders and FGIDs. In this review, we discuss FD, gastroparesis, IBS, functional constipation, and functional diarrhea. The rationale for the inclusion of only a 
few of these disorders is based on the recent findings such as; $i$. FD and IBS are the most common among all FGIDs (Sperber et al., 2021a), ii. Several reports noted FD and IBS have substantial overlap of clinical symptoms and pathophysiological mechanisms (Black and Ford, 2020), iii. FD patients (particularly FD-PDS) often overlap (90\%) with gastroparesis and further, gastroparesis has clinical overlap with functional constipation (66\%) (Parkman et al., 2011; Zikos et al., 2019; Ghoshal et al., 2021), iv. A recent study showed that FD and gastroparesis's clinical features and pathological mechanisms are very similar, and the question arose if they should even be categorized as two separate conditions (Pasricha et al., 2021), and, v. Further, the management of IBS-C and functional constipation is the same. Similarly, the management of IBS-D and functional diarrhea are the same; therefore, we also covered functional constipation and functional diarrhea. For this review, literature searches were performed using PubMed from June 2021 through November 2021 to identify publications reporting on the pathophysiology, diagnostic criteria, and treatments options for FD, gastroparesis, IBS, functional constipation, and functional diarrhea. We selected 184 references for inclusion in this review due to their relevance in regard to the scope of this manuscript and based on the authors' insight, research experience, and clinical practices in managing these disorders.

\section{PATHOPHYSIOLOGICAL MECHANISMS OF MOTILITY DISORDERS AND FGIDs}

Gut motility disorders and FGIDs are extremely diverse conditions. Therefore, understanding the molecular and cellular mechanisms underlying the pathology of these conditions is essential for the more effective treatment of these disorders. Multiple pathophysiological mechanisms are involved in the development of these disorders.

\section{Altered Gut Motility}

Proper propulsion of food through the gut relies on peristaltic movements (Sanders et al., 2012). ICCs, enterochromaffin (EC) cells, the enteric nervous system (ENS), and GI smooth muscle cells are some of the most important factors regulating peristalsis of both longitudinal and circular smooth muscle (Grover et al., 2011; Mazzone et al., 2020; Spencer and Hu, 2020; Jin et al., 2021; Singh et al., 2021a; Singh et al., 2021b; Singh et al., 2021c; Wei et al., 2021a; Zheng et al., 2021). Further, functional defects of particular GI cells, for instance, ICCs, SMCs, EC cells, enteric neurons, and immune cells can hamper gut peristalsis (Figure 1). Gut dysmotility caused by impaired peristalsis is a key pathophysiological mechanism of these disorders (Shin et al., 2019; Spencer and Hu, 2020).

\section{Gut Microbial Dysbiosis}

Gut microbial dysbiosis is highly overrepresented in FGIDs, particularly in IBS and FD. (Barbara et al., 2016b; Wei et al., 2021b; Singh et al., 2021d). Moreover, gut immune dysfunction, altered gut-brain axis, visceral hypersensitivity, impaired gut epithelial barrier function, altered gut motility, along with other pathophysiological mechanisms, have been demonstrated in gut microbial dysbiosis (Backhed et al., 2005; Barbara et al., 2016b; Cani, 2017; Shin et al., 2019; El-Salhy et al., 2021). Increased understanding of host-microbe interactions has shed light on the key pathophysiological role that microbes play in developing FGIDs (Schroeder and Backhed, 2016). Activation of the mucosal immune response via disruption of the gut microbial composition leads to gut barrier dysfunction, also known as the leaky gut. The development of a leaky gut also causes gut dysmotility and visceral hypersensitivity, which are pathophysiological characteristics of FGIDs (Barbara et al., 2016b; Singh et al., 2021d). While many studies have highlighted the possibility that altered gut microbial composition may trigger the development of FGIDs, it is not currently clear if this connection is more than merely a correlation (Malinen et al., 2005; Shukla et al., 2015; Ghoshal et al., 2018; Mars et al., 2020). It should be noted that disease progression can also be affected by the host diet, immune response, and host environment. Additionally, the interactions between the host and the gut microbiota or microbial-produced metabolites modulate the gut-brain physiology.

Metabolites generated by the gut microbiota continually signal to the hosts' organs and regulate pathophysiological mechanisms during both health and disease (Sekirov et al., 2010; Schroeder and Backhed, 2016). Short-chain fatty acids (SCFAs) are key fermentation products produced by the microbiota in our gut. IBS-C patients have decreased SCFAs (propionate and butyrate), and patients with IBS-D have increased butyrate levels compared to healthy controls (HCs), emphasizing the significant role of SCFAs in regulating gut motility (Sun et al., 2019). Further, microbiota-produced SCFAs interact with EC cells and enhance the expression of tryptophan hydroxylase 1 (Tph1), which finally increases the production of serotonin in the gut of both mice and humans (Reigstad et al., 2015). Moreover, tryptamine (a monoamine, like serotonin, that is derived from tryptophan) has been shown to improve gut motility acting through 5-HT4 receptors located on colonic epithelial cells in mice (Williams et al., 2014; Bhattarai et al., 2018). Moreover, microbial dysbiosis-induced BA pool alternations might be a key pathological mechanism of FGIDs. Gut dysmotility and visceral pain are associated with elevated BA levels in IBS-D patients (Mars et al., 2020). Taken together, host physiology is greatly impacted by microbe-derived metabolites and may be targets of future therapeutic options for patients with FGIDs.

\section{Gut Immune Dysfunction}

A subset of FGID patients have been shown to have dysfunction of their gut immune response (Muller et al., 2014; Grover et al., 2018; Black et al., 2020b; Gottfried-Blackmore et al., 2021; Ji et al., 2021). For example, an increase in the amount of immune cells in the gut (such as mast cells, T cells, macrophages, and eosinophils) of FGID patients has been reported in multiple studies (Barbara et al., 2011; Matricon et al., 2012; Barbara et al., 2016b; Singh et al., 
2017). Activated mast cells release cytokines, histamines, prostaglandins, and tryptase, which are associated with intestinal barrier dysfunction and altered nociceptive pathways in FGIDs (Barbara et al., 2004; Barbara et al., 2007; Dothel et al., 2015; Aguilera-Lizarraga et al., 2021). Intestinal barrier dysfunction leads to the permeation of pathogens and food antigens, which causes a heightened immune response in the gut and greatly impacts the severity of symptoms experienced by patients with FGIDs (Camilleri et al., 2012; Wouters et al., 2016b).

\section{Intestinal Barrier Dysfunction}

The gut luminal-mucosal interface contains food particles along with many other molecules that can induce immunogenic responses creating a constant challenge for the gut immune system (Ghoshal, 2020). As a core pathophysiological mechanism, dysfunction of the intestinal barrier activates the gut immune response, which can hamper gut function and increase the symptom severity in patients with FGIDs (Barbara et al., 2016b; Wouters et al., 2016b). The gut epithelium is an astounding barrier that allows for the selective absorption of essential nutrients, water, and electrolytes, while preventing harmful toxins, metabolites, and pathogens from penetrating the gut epithelium (Camilleri, 2019). Epithelial tight junction proteins help to maintain this selective barrier to prevent harmful molecules from penetrating the epithelium while allowing for the passage of essential nutrients (Camilleri, 2019; Motta et al., 2021). Decreased expression of these tight junction proteins, caused by genetic, pathogenic, or other factors, leads to intestinal barrier dysfunction (Bischoff et al., 2014; Desai et al., 2016; Martinez et al., 2017; AguileraLizarraga et al., 2021). Several studies have shown the decreased expression of zonula occludens-1, occludin, and adhesion proteins, as well as decreased transepithelial resistance in duodenal biopsies from FGIDs patients compared to HCs, suggesting impaired intestinal barrier function in a subset of these disorders (Bertiaux-Vandaele et al., 2011; Turcotte et al., 2013; Fritscher-Ravens et al., 2014; Lee et al., 2020). Thus, healthy gut barrier integrity is critical for host defense, pathogen colonization resistance, and, more importantly, gut homeostasis.

\section{Visceral Hypersensitivity}

Gut bacteria and their derived molecules, along with food particles are recognized and transduced through interaction with receptors on neuroimmune cells and enteroendocrine cells (Sternini et al., 2008). Visceral sensitivity is affected by the gut immune response in a manner relative to the proximity of neurons to immune cells as well as the propagation level of inflammatory reactions (Barbara et al., 2004; Aguilera-Lizarraga et al., 2021). More importantly, visceral hypersensitivity is a key pathophysiological mechanism leading to the development of FGIDs (Singh et al., 2016; Black et al., 2020b; Grover et al., 2021). Visceral hypersensitivity can be explained by an increased perception of gut mechano-chemical stimulation, which typically manifests in an aggravated feeling of pain and burning (Farzaei et al., 2016; Bellono et al., 2017). Activation of transient receptor potential vanilloid subtype 1 (TRPV1) is triggered by nerve growth factor (NGF), thermal stimulus, capsaicin, prostaglandins, acidic $\mathrm{pH}$, and inflammatory mediators, which further release neuropeptides that aid in visceral pain sensation. (Farzaei et al., 2016). Furthermore, upregulation of TRPV1 has been associated with abdominal pain in IBS patients in a plethora of studies (Akbar et al., 2008; Grover et al., 2021).

\section{Altered Gut-Brain Interactions}

Gut function is heavily influenced by the coordinated communication between the gut and brain (Quigley, 2017). This bi-directional interaction is essential for normal gut motility, visceral sensation, intestinal barrier integrity, gastric secretions, and immune response (Rhee et al., 2009). Just as the brain has a fundamental role in the maintenance of normal gut functions, the gut also has a vital role in modulating brain function. The gut-brain axis also aids in indirect signaling between the host and gut microbiota; for instance, gut microbial-induced epithelial barrier dysfunction alters this bidirectional interaction (Carabotti et al., 2015). The emotional motor system enables the perception of gut stimuli and modulates several gut functions (Needham et al., 2020). Consequently, alterations to the gut microbiota may regulate neurotransmitter synthesis or consumption, leading to emotional state and behavior alterations (Van Oudenhove et al., 2016). Many patients with FGIDs also experience psychological conditions such as stress, anxiety, and depression, indicating these conditions play a significant part in the development of FGIDs (Drossman et al., 2018). In addition, patients with FGIDs have been shown to have both abnormal structure and functional networks in parts of the brain that process information such as the visceral motor system and vagovagal reflux, as evidenced by functional brain MRI studies (Enck et al., 2017; Guleria et al., 2017; Ford et al., 2020). Taken together, it is clear that impaired brain function can lead to altered gut physiology, such as gut dysmotility and heightened visceral sensitivity, underpinning the symptoms of FGIDs. Further, dysregulated gut homeostasis can also lead to physiological changes in the brain, significantly hampering psychological health.

\section{PATHOPHYSIOLOGY-DIRECTED THERAPEUTIC APPROACH FOR MOTILITY DISORDERS AND FGIDs}

New therapeutics that focus on treating the underlying pathophysiological mechanisms contributing to the development of motility disorders and FGIDs are necessary to treat these patients better. FGIDs have substantial clinical overlap with specific gut motility disorders (Black and Ford, 2020; Ghoshal, 2020). Further, a multinational study conducted in 26 countries demonstrated substantial negative ramifications on the quality of life and increased psychological comorbidity for the patients who experienced multiple FGIDs (Sperber et al., 2021b). Common pathophysiological mechanisms between different FGIDs lead to the significant overlap of these 
TABLE 1 | Pathophysiology based pharmacological agents modulating peripheral and central factors for gastrointestinal dysmotility and functional gastrointestinal disorders.

$\begin{array}{ccc}\text { Drug class } & \begin{array}{c}\text { Pathophysiological } \\ \text { mechanism }\end{array} & \text { Mechanism of action }\end{array}$

Pharmacological agents modulating peripheral factors

$\begin{array}{lll}\text { 5-HT4R agonists } \quad \text { Altered gut motility } & \text { 5-HT4R agonists target 5-HT4Rs on } & \text { Improves gut motility. Improves GI } \\ & \text { interneurons and excitatory motor neurons, symptoms as assessed by the GCSI } & \text { Simren and Tack (2018); } \\ & \text { enhancing the release of acetylcholine, which } & \text { further promotes peristalsis and secretion }\end{array}$

5-HT3R Altered gut motility

antagonists

further promotes peristalsis and secretion

Patients with IBS-D have abnormal

serotonergic transmission mediated through

the 5-HT3Rs. Blocking 5-HTRs causes

increases fluid absorption, slows gut transit, and reduces colonic contractility

5-HT1AR agonists Altered gut motility

Activation of 5-HT1AR at the level of the CNS increases gastric tone and decreases gastric sensitivity to distensionPeripheral inhibitory effect exerted by the 5-HT1AR agonist improves gastric accommodation

Ghrelin receptor Altered gut motility agonists

Stimulates ghrelin receptors that present on vagal afferents and dorsal motor nucleus of the vagus neurons innervated across the $\mathrm{Gl}$

Muscarinic Altered gut motility

receptor

antagonists

FXR agonists

IBAT antagonists

Altered bile acid secretion

Altered bile acid secretion

Mast cell stabilizer

Gut immune dysfunction

Histamine

receptor-1

antagonists

$\mathrm{CCl} 2$ agonists

Altered Gl secretion

Guanylate cyclaseC receptor agonists

Altered Gl secretion

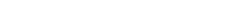

$\mu$-Opioid receptor Visceral hypersensitivity ligands

Cannabinoid type 2 Visceral hypersensitivity receptor agonists
Increases acetylcholine levels in the synaptic cleft through inhibition of acetylcholinesterase and antagonization of the presynaptic muscarinic receptors that are present on cholinergic nerve endings

Inhibits hepatocyte bile acid synthesis, resulting in decreased colonic bile acid concentration

IBAT antagonists block the function of ASBT that is present on epithelial cells in the ileum leading to inhibition of bile acid reabsorption and subsequently increasing colonic secretion

The generation of hypersensitivity and gut immune dysfunction is largely influenced by mast cells

Histamine sensitizes TRPV1+ neurons in colonic biopsies from IBS patients

Increases the sodium and water secretion into the lumen by activating the $\mathrm{CCl} 2$ channels present on enterocytes

Transmembrane GC-C receptors are located on IECs and regulate electrolyte and fluid balance in the gut and therefore help to maintain normal bowel function. Activation of GC-C receptors increases intracellular cyclic guanosine monophosphate that helps to increase colonic fluid secretion

Recruits $\beta$-arrestin and facilitates the receptor internalization and desensitization, thereby activating $\mu$-ORs in endosomes and inducing analgesia

CB2R agonists reduce pain as it reduces visceromotor response to colorectal distention
Globally improves IBS symptoms, relieves abdominal pain and discomfort, and improves stool consistency and bowel movements

Enhances fundus relaxation, gastric accommodation, and improves postprandial symptoms independently from its anxiolytic effect

Improves delayed gastric emptying in diabetic gastroparesis condition

Improves gut motility and is also beneficia as antispasmodics increasing colonic bile acids
Improves stool form and symptoms of diarrhea

Efficacious treatment for constipation, improving gut transit and symptoms via

Reduces IBS symptoms by improving the visceral pain threshold in IBS patients

Reduces visceral pain and hypersensitivity in IBS patients

Improves gut motility along with the frequency and consistency of stool. Reduces abdominal pain, bloating, and straining

Improves the frequency and consistency of Rao et al. (2012) stool and reduces straining. Reduces abdominal pain, bloating, and cramping

Manages both severe and moderate acute pain in adults that were unable to be treated with alternative medicines (excluding opioids)

Has potential analgesic effects in patients Castro et al. (2021) with IBS

Walters et al. (2015); Camilleri et al. (2020b)

Vijayvargiya et al. (2018)

Klooker et al. (2010)

Wouters et al. (2016a)

Drossman et al. (2009)

Markham, (2020)

\author{
Affects gut motility through anticholinergic Mertz et al. (1998) \\ and serotonergic mechanisms. Reduces \\ visceral hypersensitivity and intestinal pain \\ sensitivity via mediation of either periphera \\ nerves or the CNS
}

Primarily used for anti-depressant and analgesic purposes, additionally, they can block opioid receptor activation, voltagegated ion channels and modulate neuroimmune anti-inflammatory effects 
TABLE 1 | (Continued) Pathophysiology based pharmacological agents modulating peripheral and central factors for gastrointestinal dysmotility and functional gastrointestinal disorders.

\begin{tabular}{|c|c|c|c|c|}
\hline Drug class & $\begin{array}{l}\text { Pathophysiological } \\
\text { mechanism }\end{array}$ & Mechanism of action & Clinical outcome & References \\
\hline TeCAs & & $\begin{array}{l}\text { Boosts NA and } 5 \text {-HT neurotransmission by } \\
\text { blocking presynaptic } \alpha 2 \text {-noradrenergic } \\
\text { receptors on noradrenaline and serotonergic } \\
\text { neurons }\end{array}$ & $\begin{array}{l}\text { Orexigenic hormones are upregulated, and } \\
\text { anorexigenic hormones are } \\
\text { downregulated, reducing colonic } \\
\text { hypersensitivity and improving gastric } \\
\text { emptying }\end{array}$ & Tack et al. (2016) \\
\hline \multirow[t]{2}{*}{ SSRls } & & $\begin{array}{l}\text { Boosts serotonergic transmission by selective } \\
\text { blockage of 5-HT transporter }\end{array}$ & Increases colonic motility & $\begin{array}{l}\text { Tornblom and Drossman, } \\
\text { (2015) }\end{array}$ \\
\hline & & & $\begin{array}{l}\text { Decreases symptoms of IBS scores for } \\
\text { bloating and abdominal pain independent } \\
\text { of centrally modulating functions }\end{array}$ & \\
\hline SNRIS & & $\begin{array}{l}\text { Boosts NA and } 5-\mathrm{HT} \text { neurotransmission by } \\
\text { blocking their reuptake }\end{array}$ & $\begin{array}{l}\text { Increases compliance, relaxes tone, } \\
\text { reduces the postprandial colonic } \\
\text { contraction, and increases sensory } \\
\text { thresholds in response to balloon } \\
\text { distensions }\end{array}$ & $\begin{array}{l}\text { Tornblom and Drossman, } \\
\text { (2015) }\end{array}$ \\
\hline
\end{tabular}

Pharmacological agents modulating both central and peripheral factors

Selective NK1

receptor

antagonists

\begin{abstract}
Reduce the onset of emesis by affecting regions of the brain that cause vomiting and nausea through competition for NK1 receptors on vagal afferents or inhibition of major effects of substance $P$ on key emetic pathways. Modulates the functional interplay between NK1R systems and acetylcholine, which causes stimulation of smooth muscle contractions
\end{abstract}

Improves both GCSI and nausea scores in Carlin et al. (2021) patients with gastroparesis

\author{
Orexigenic hormones are upregulated, and Tack et al. (2016) \\ hypersensitivity and improving gastric \\ emptying \\ Decreases symptoms of IBS scores for \\ of centrally modulating functions \\ Increases compliance, relaxes tone \\ sostprandial colonic \\ distensions \\ Tornblom and Drossman, \\ (2015) \\ Tornblom and Drossman, \\ (2015)
}

\section{.}


disorders and FGIDs (Pimentel et al., 2006; Ghoshal et al., 2011b; Ghoshal et al., 2018). For example, interventional studies reported that IBS-C and functional constipation patients have decreased breath $\mathrm{CH}_{4}$ following treatment with rifaximin alone or a combination of rifaximin and neomycin, which improved the constipation phenotype (Pimentel et al., 2006; Ghoshal et al., 2018). Further, FD patients treated with rifaximin demonstrated improved dyspeptic symptoms, including belching and abdominal bloating/fullness in randomized controlled trials (Iovino et al., 2014). Moreover, meta-analysis and systematic reviews have demonstrated the efficacy of rifaximin and other antibiotics in treating small intestinal bacterial overgrowth (SIBO) (Gatta and Scarpignato, 2017).

In patients with $\mathrm{FD}$, there is frequently the presence of Helicobacter pylori (H. pylori) infection (40-70\%) (Ghoshal et al., 2011a; Naz et al., 2013; Kim et al., 2017; Rahman et al., 2021). The exact role of $H$. pylori infection in the development of FD symptoms remains controversial and it is not clear if it is an association and/or causation (Masuy et al., 2019b). Randomized controlled trials reported substantial symptom improvement after $H$. pylori eradication therapy (McColl et al., 1998; Bruley Des Varannes et al., 2001; Malfertheiner et al., 2003; Mazzoleni et al., 2011; Kim et al., 2013; Du et al., 2016). In contrast, several studies failed to confirm convincing results for the superiority of H. pylori eradication therapy over placebo groups to improve FD symptoms (Talley et al., 1999a; Talley et al., 1999b; Miwa et al., 2000; Veldhuyzen van Zanten et al., 2003; Zhao et al., 2013). However, owing to the improvement of symptoms in a subset of patients with FD, eradication of $H$. pylori is recommended as a first-line therapy in H. pylori associated-FD patients (Camilleri and Stanghellini, 2013; Suzuki and Moayyedi, 2013; Talley and Ford, 2015; Enck et al., 2017; Suzuki, 2017).

Along with probiotics and antibiotics, FMT has been shown to restore a balanced microbiota and is a potential treatment option for gut microbial dysbiosis (Khoruts and Sadowsky, 2016). However, it is still unclear whether FMT treatment for patients with FGIDs actually helps them or merely causes a placebo effect (Pulipati et al., 2020; Shanahan et al., 2021). Further, IBS patients' symptoms were not significantly improved following FMT treatment when compared to the placebo group in a recent meta-analysis (Ianiro et al., 2019). In contrast, IBS patients' symptom severity was significantly improved following treatment with FMT when compared to placebo (El-Salhy et al., 2020). Therefore, larger, more meticulous, and multicentric studies are warranted to accurately assess the benefit of FMT.

\section{Pharmacological Agents Modulating Gut Immune Dysfunction}

Increased mast cell number, pro-inflammatory M1 macrophages, and lymphocytes are characteristics of gut immune dysfunction and might be involved in the pathophysiology of gut motility disorders and FGIDs (Matricon et al., 2012). Additionally, ketotifen [A clinical trial (registration number NTR39, ISRCTN22504486) in the Netherlands], a mast cell stabilizer, was shown to increase the discomfort thresholds to rectal distension, improving abdominal pain in a subset of IBS patients (Klooker et al., 2010). However, mesalazine [ClinicalTrials.gov: NCT00626288 (phase 3)], an antiinflammatory drug, failed to show any benefit in controlled trials on
IBS (Barbara et al., 2016a). In a gastroparesis animal model, one study demonstrated that oxidative stress and damage of the pacemaker cells or enteric nerves was caused by depletion of resident M2 anti-inflammatory macrophages that express heme oxygenase-1 (HO-1) (Choi et al., 2010; Bharucha et al., 2016). However, gastric emptying was not significantly improved in a randomized-controlled trial following treatment with hemin, a HO-1-inhibitor in humans (Bharucha et al., 2016). Furthermore, patients with FD showed reduced number of mast cells and duodenal eosinophils, as well as reduced intestinal permeability and symptom severity when treated with proton pump inhibitors (Wauters et al., 2021). Further, the reduction of eosinophils was associated with clinical efficacy in these patients.

\section{Pharmacological Agents Modulating Visceral Hypersensitivity}

A murine model of visceral hypersensitivity, along with a subset of IBS patients, demonstrated HRH1 activation, which leads to increased submucosal neuronal responses to the TRPV1-agonist, capsaicin (Wouters et al., 2016a). Ebastine [ClinicalTrials.gov: NCT01908465 (phase 4)], the HRH1-antagonist, was found to reduce abdominal pain in a state-of-the-art study on IBS patients (Wouters et al., 2016a). Visceral analgesics, such as biased $\mu$-OR ligands and CB2R agonists have proven to improve symptoms in patients with IBS (Camilleri, 2021). G protein-mediated pathways and beta-arrestin recruitment are activated by $\mu$-OR-agonists that induce analgesia while mediating receptor internalization and desensitization, triggering the activation of $\mu$-ORs in endosomes, and inhibiting gut motility (Raehal et al., 2011). The $\mu$-ORagonist, oliceridine, has been shown to help manage moderate or severe acute pain in patients who have not seen symptom improvement while taking other treatments (excluding opioids) (Markham, 2020). Furthermore, an animal model of visceral hypersensitivity had reduced visceromotor response to colorectal distension when treated with olorinab [ClinicalTrials.gov: NCT04655599 (phase 1)], a CB2R agonist (Castro et al., 2021). More importantly, olorinab may have exceptional efficacy in IBS patients, likely due to its potential analgesic effects; however, to confirm these results, more robust studies are needed. Neuromodulators are also used for the treatment of visceral hypersensitivity in patients with FGIDs (Drossman et al., 2018; Simren and Tack, 2018). Studies have demonstrated that TCAs, particularly amitriptyline, reduce visceral hypersensitivity in patients with IBS (Poitras et al., 2002; Morgan et al., 2005; Thoua et al., 2009). Dysregulated gut-brain interaction is a major pathophysiological mechanism in patients with FGIDs. This further reinforces that central neuron degeneration might be involved in the development of abdominal pain (Tornblom and Drossman, 2015; Drossman et al., 2018).

\section{Pharmacological Agents Modulating Altered GI Secretion}

Modulation of altered GI secretion in chronic constipation and IBS-C patients via pharmacological agents for $\mathrm{GC}-\mathrm{C}$ receptors and chloride channels on intestinal epithelium cells has been well studied 
(Pannemans and Tack, 2018). The maintenance of bowel function through fluid and electrolyte regulation is modulated by the gut GC$\mathrm{C}$ receptors expressed by intestinal epithelial cells. The activation of GC-C receptors leads to the development of an ion gradient between the gut lumen and intestinal epithelium, which stimulates water movement in the lumen through the concurrent inhibition of sodium/hydrogen exchanger isoform three channels and activation of cystic fibrosis transmembrane conductance regulator (CFTR) channels (Brancale et al., 2017). Treatment with Linaclotide (approved in most parts of the world for treating IBS-C and chronic constipation), a GC-C receptor agonist, accelerated colonic transit and softened stool in patients with IBS-C (Chey et al., 2012; Rao et al., 2012; Black et al., 2018; Islam et al., 2018).

Fluid secretion and gut motility are regulated by intestinal epithelial cells' chloride channels (Jiang et al., 2015). Chloride ions are released into the lumen of the intestine via activation of type- 2 chloride channels. This results in an ion gradient, which promotes the release of water and sodium into the gut lumen and therefore increases stool volume and accelerates gut motility. The locally acting selective type-2 chloride channel agonist Lubiprostone [United States Food and Drug Administration (U.S. FDA) approved medicine for treating patients with IBS$\mathrm{C}$ and chronic constipation and is also approved for the treatment of IBS-C and chronic constipation in many other countries)] has been shown to improve the frequency and consistency of stool, which leads to reduced constipation, bloating, and straining in patients with IBS-C and functional constipation (Johanson et al., 2008; Drossman et al., 2009; Black et al., 2018).

\section{Pharmacological Agents Modulating Altered Bile Acid Secretion}

IBAT inhibitor and FXR agonists have been proposed to modulate altered BA secretion in chronic constipation, IBS-C, and IBS-D patients (Vijayvargiya et al., 2018; Vijayvargiya and Camilleri, 2019; Khanna and Camilleri, 2021). Elobixibat [ClinicalTrials.gov: NCT01007123 (phase 2)] is an IBAT inhibitor that hinders the reabsorption of BA in the gut (Khanna and Camilleri, 2021). This results in increased concentrations of BA in the colon, promotes fluid secretion, and rescues colonic dysmotility. Treatment with Elobixibat leads to improved symptoms associated with constipation, including straining, constipation severity, stool consistency, stool frequency, and abdominal bloating in patients with IBS-C and functional constipation (Khanna and Camilleri, 2021). In contrast, since FXR agonists, obeticholic acid (US. FDA approved medicine) and tropifexor [ClinicalTrails.gov: NCT02713243 (phase 2)], inhibit hepatocyte BA synthesis, that further leads to a reduction in BA concentration in the colon's lumen, which rescues diarrhea symptoms (Walters et al., 2015; Camilleri et al., 2020b).

\section{Pharmacological Agents Modulating an Altered Gut-Brain Axis}

Neuromodulators TCA, TeCA, SNRIs, and SSRIs are frequently used as a second-line treatment options for patients with FGIDs, particularly IBS (Drossman et al., 2018). TCAs inhibit the reuptake of noradrenaline (NA) and 5-HT and have demonstrated potential for their anti-depressant and analgesic effects (Tornblom and Drossman, 2015). In contrast, TeCAs block presynaptic $\alpha 2$ noradrenergic receptors on NA and 5-HT neurons resulting in increased NA and 5-HT neurotransmission (Tornblom and Drossman, 2015). SSRIs boost the neurotransmission of 5-HT by blocking the presynaptic 5-HT transporter. However, the effect of these drugs is more beneficial in the treatment of psychological disorders than chronic pain syndromes. Finally, SNRIs block the reuptake of both the 5-HT and NA, boosting their neurotransmission and modulating pain sensation (Tornblom and Drossman, 2015).

These findings suggest that pathophysiology-directed therapeutic modalities could provide precise clinical outcomes in FGIDs as there is significant clinical overlap among FGIDs.

\section{CURRENT TREATMENT OPTIONS FOR MOTILITY DISORDERS AND FGIDS}

The best treatment approach for motility disorders and FGIDs would be to fix the cellular and molecular defects linked with the pathophysiological mechanisms, which would also improve cardinal GI symptoms. However, GI symptoms in motility disorders and FGIDs may not always reflect the underlying pathophysiological mechanisms. Further, without knowing the exact pathologies, the treatment approach might be ineffective and result in higher healthcare expenditure and poor patient quality of life, suggesting that pathophysiology-directed therapeutic strategies might be a better therapeutic approach. Here, we have discussed available treatment options and pathophysiology-based therapeutic options for gastroduodenal motility disorders (FD and gastroparesis) and bowel disorders (IBS-C/functional constipation and IBS-D/functional diarrhea). Some medications discussed in this review for motility disorders and FGIDs are not FDA approved but are approved and available for clinical use in Europe, Asia, and/or Latin America.

\section{Candidate Drugs for Gastroduodenal Motility Disorders}

In Table 2, we have summarized the candidate drugs for gastroparesis and FD.

\section{PROKINETIC AGENTS}

Based on previous clinical trials and meta-analyses, prokinetics have been recommended to treat gastroparesis, FD, IBS-C, and chronic constipation (Simren and Tack, 2018; Carbone et al., 2019; Grover et al., 2019; Camilleri and Atieh, 2021; Sharma et al., 2021). The pharmacological classes of prokinetics include serotonin 5-HT4R agonists, 5-HT1AR agonists, ghrelin receptor agonists, dopamine-2 receptor antagonists, and muscarinic receptor antagonists.

\section{5-HT4R Agonists}

Prucalopride [ClinicalTrials.gov: NCT02031081 (phase 2), NCT02510976 (phase 4)], a 5-HT4R agonist, exerts both 
TABLE 2 | Currently available pharmacological agents for gastroduodenal motility disorders.

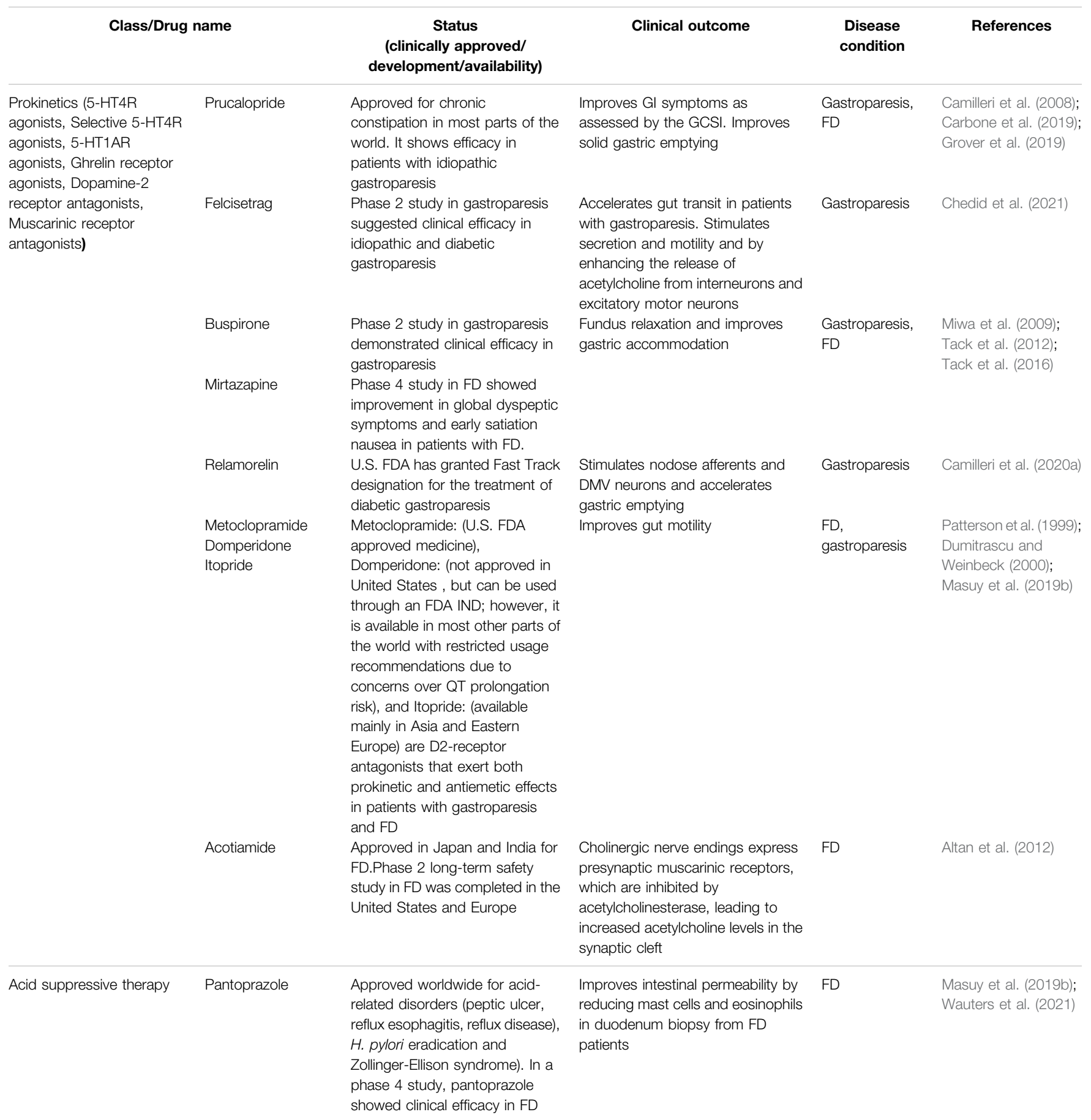

Abbreviations: 5-HT1AR: 5-hydroxytryptamine receptor 1A, GCIS: gastroparesis cardinal symptom index, FD: functional dyspepsia, IBS-C: constipation-predominant IBS, DMV: dorsal motor nucleus of the vagus.

gastro- and enterokinetic effects, which improves GI symptoms when assessed by the gastroparesis cardinal symptom index (GCSI) (Carbone et al., 2019). Felcisetrag [ClinicalTrials.gov: NCT03281577 (phase 2)] and Velusetrag [ClinicalTrials.gov: NCT01718938 (phase 2)] are additional selective 5-HT4R agonists that have gut prokinetic effects (Chedid et al., 2021; Kuo et al., 2021). They were shown to induce symptom relief and accelerate GI transit in idiopathic or diabetic gastroparesis patients (Chedid et al., 2021; Kuo et al., 2021). Defects in gut motility, including impaired fundus accommodation and delayed gastric emptying, have been shown in a subset of patients with FD (Asano et al., 2017; Enck et al., 2017). Further, treatment with prokinetic agents typically restores impaired gastric-duodenal motility in patients with FD-PDS (Masuy et al., 2019b). 


\section{5-HT1AR Agonists}

Buspirone [ClinicalTrials.gov: NCT03587142 (phase 2)], a 5-HT1AR agonist, improves gastric accommodation and postprandial symptoms in patients with FD (Tack et al., 2012). Another 5HT1AR agonist, Tandospirone, has shown significant resolution in FD symptoms compared to the placebo-treated group in a multicenter study (Miwa et al., 2009). Mirtazapine [ClinicalTrials.gov: NCT01240096 (phase 4)]), a TeCA with 5-HT1AR agonist activity on central and peripheral 5-HT1AR, leads to gastric fundus relaxation with improved nutrient volume tolerance, global dyspeptic symptoms, and early satiation nausea in patients with FD (Tack et al., 2016). Further, recent reports noted that mirtazapine improves nausea, vomiting, and loss of appetite in patients with gastroparesis (Malamood et al., 2017; Marella et al., 2019).

\section{Ghrelin Receptor Agonists}

Relamorelin (US. FDA approved medicine), a ghrelin receptor agonist, stimulates nodose afferents and dorsal motor nucleus of the vagus neurons, while accelerating gastric emptying and improving pain, nausea, bloating, and fullness in diabetic gastroparesis patients (Chedid and Camilleri, 2017; Camilleri et al., 2020a).

\section{Dopamine-2 Receptor Antagonists}

Metoclopramide (US. FDA approved medicine), domperidone (not approved in United States, but can be used through an FDA IND, due to concerns over its cardiac side effects. In Europe, domperidone has long been available over the counter; however, based on recent concerns over risk for prolongation of the QT-interval and increased risk of ventricular arrhythmia, it has only limited availability in Europe on a prescription basis, and only short-term use is recommended), and itopride [ClinicalTrials.gov: NCT00110968 (phase 3)], available mainly in Asia and to some extent in Eastern Europe are D2-receptor antagonists that exert both prokinetic and antiemetic effects in patients with gastroparesis and FD (Patterson et al., 1999; Dumitrascu and Weinbeck, 2000; Masuy et al., 2019b). Treatment with metoclopramide may result in adverse reactions, including a very serious condition called tardive dyskinesia. Additionally, there is an FDA black box warning for long-term use of metoclopramide (Rao and Camilleri, 2010).

\section{Muscarinic Receptor Antagonists}

Acotiamide [ClinicalTrials.gov: NCT03402984 (phase 2)], a muscarinic receptor antagonist (acetylcholinesterase inhibitor), antagonizes the presynaptic muscarinic receptors and has a prokinetic effect throughout the gut (Altan et al., 2012; Masuy et al., 2019a) and has been developed and approved in Japan and India for the treatment of FD. Studies have shown its efficacy in improving impaired gastric accommodation in patients with FD (Altan et al., 2012; Matsueda et al., 2012).

\section{SELECTIVE NK1 RECEPTOR ANTAGONISTS}

There is extraordinary potential for neurokinin-1 (NK1) or tachykinin receptor antagonists since they are effective both as antiemetics and gastrokinetics (Carlin et al., 2021). As antiemetic agents, they reduce the onset of emesis by affecting regions of the brain that cause vomiting and nausea through competition for NK1 receptors on vagal afferents or inhibition of significant effects of substance $\mathrm{P}$ on key emetic pathways. As gastrokinetics, they stimulate smooth muscle contractions in the stomach (Jacob et al., 2017). Tradipitant [ClinicalTrials.gov: NCT04028492 (phase 3)], a NK1 receptor antagonist, has been tested in patients with gastroparesis, and it showed improvement in GCSI, particularly nausea and vomiting scores (Jacob et al., 2017; Carlin et al., 2021).

\section{ACID SUPPRESSIVE THERAPY}

Patients with FD have duodenal hypersensitivity to gastric acid as well as impaired duodenal clearance of gastric acid, which highlights acid suppression therapy as a possible treatment for FD (Moayyedi et al., 2004). Acid suppression therapy is approved worldwide for acid-related disorders (peptic ulcer, reflux esophagitis, reflux disease, H. pylori eradication and Zollinger-Ellison syndrome). The first-line therapy for FD patients is acid suppression with proton pump inhibitors (PPIs), for instance lansoprazole, rabeprazole, pantoprazole, and omeprazole, although this may be the most commonly effective for the groups that have both EPS-FD and FD-GERD (Masuy et al., 2019b). Furthermore, a proof-of-concept study showed that pantoprazole [ClinicalTrials.gov: NCT03545243 (phase 4)] reduced duodenal eosinophils, mast cells, and intestinal permeability, which were correlated with a better clinical outcome in FD patients (Wauters et al., 2021).

\section{Candidate Drugs for Bowel Disorders}

In Table 3, we have summarized the candidate drugs for IBS, functional constipation, and functional diarrhea.

\section{PROKINETICS}

\section{5-HT4R Agonists}

5-HT4R agonists accelerate gut transit (Simren and Tack, 2018; Ghoshal, 2020). Gut motility was substantially improved in IBS-C patients treated with Tegaserod when compared to the placebotreated patients (Black et al., 2020a) (Johanson et al., 2004). This drug led to a slight increase in cardiovascular and cerebrovascular ischaemic events, and therefore use was discontinued. The US. FDA approved reintroduction of tegaserod in 2019 for female patients with IBS that had no history of cardiovascular disease and were younger than 65 years old (Shah et al., 2021). Further, there were no significant cardiovascular events related to tegaserod observed in patients with $\leq 1$ cardiac risk factor in this study. Prucalopride (approved for chronic constipation in most parts of the world) is another 5-HT4R agonist that demonstrated significantly improved chronic-constipation symptoms when compared to the placebo-treated group; however, IBS-C studies lack randomized controlled trials (Camilleri et al., 2008). 
TABLE 3 | Currently available pharmacological agents for bowel disorders.

\begin{tabular}{|c|c|c|c|c|c|}
\hline \multicolumn{2}{|c|}{ Class/Drug name } & \multirow{2}{*}{$\begin{array}{l}\begin{array}{c}\text { Status (clinically approved/ } \\
\text { development/availability) }\end{array} \\
\text { Prucalopride is approved for } \\
\text { chronic constipation in most } \\
\text { parts of the world.The U.S. FDA } \\
\text { approved reintroduction of } \\
\text { tegaserod in } 2019 \text { for female } \\
\text { patients (younger than } 65 \text { years } \\
\text { old) with IBS-C }\end{array}$} & \multirow{2}{*}{$\begin{array}{l}\text { Clinical outcome } \\
\text { Improves GI symptoms as } \\
\text { assessed by the GCSI. } \\
\text { Improves solid gastric } \\
\text { emptying }\end{array}$} & \multirow{2}{*}{$\begin{array}{l}\begin{array}{l}\text { Disease } \\
\text { condition }\end{array} \\
\text { IBS-C/ } \\
\text { functional } \\
\text { constipation }\end{array}$} & \multirow{2}{*}{$\begin{array}{c}\text { References } \\
\text { Camilleri et al. (2008) }\end{array}$} \\
\hline $\begin{array}{l}\text { Prokinetics (5-HT4R } \\
\text { agonists, 5-HT3R } \\
\text { antagonists) }\end{array}$ & Prucalopride, Tegaserod & & & & \\
\hline & $\begin{array}{l}\text { Alosetron, Ramosetron, } \\
\text { Ondasetron }\end{array}$ & $\begin{array}{l}\text { Alosetron: FDA approved to treat } \\
\text { only female patients with IBS-D. } \\
\text { Ramosetron: phase } 4 \text { clinical trial } \\
\text { showed clinical efficacy in male } \\
\text { patients with IBS-D. Ondasetron: } \\
\text { phase } 3 \text { clinical trial } \\
\text { demonstrated clinical efficacy in } \\
\text { patients with IBS-D, irrespective } \\
\text { of gender }\end{array}$ & $\begin{array}{l}\text { Improves stool consistency } \\
\text { and bowel movements }\end{array}$ & $\begin{array}{l}\text { IBS-D/ } \\
\text { functional } \\
\text { diarrhea }\end{array}$ & Rokkas et al. (2021) \\
\hline Antibiotics & Rifaximin & $\begin{array}{l}\text { Approved in most parts of the } \\
\text { world for the treatment of IBS. } \\
\text { Rifaximin showed clinical efficacy } \\
\text { in FD patients }\end{array}$ & $\begin{array}{l}\text { Shifts the microbial } \\
\text { community composition. } \\
\text { Improves constipation, SIBO, } \\
\text { and dyspeptics symptoms }\end{array}$ & IBS, FD & $\begin{array}{l}\text { Pimentel et al. (2011); } \\
\text { Ghoshal et al. (2018) }\end{array}$ \\
\hline Probiotics & $\begin{array}{l}\text { Bifidobacterium lactis DN- } \\
\text { 173, Lactobacillus gasseri, } \\
\text { Lactobacillus gasseri } \\
\text { OLL2716, Bifidobacterium } \\
\text { bifidum YIT10347, }\end{array}$ & $\begin{array}{l}\text { Not approved. Emerging } \\
\text { research on probiotics } \\
\text { demonstrated symptom } \\
\text { improvement in patients with IBS } \\
\text { and FD. However, probiotic } \\
\text { intervention is an active area of } \\
\text { research, and clinical outcomes } \\
\text { of probiotic strains in clinical trials } \\
\text { for IBS and FD are eagerly } \\
\text { awaited }\end{array}$ & $\begin{array}{l}\text { Modulates gut microbiota } \\
\text { profile. Improves symptoms } \\
\text { and gut transit }\end{array}$ & IBS, FD & $\begin{array}{l}\text { Aragon et al. (2010); } \\
\text { Charbonneau et al. } \\
\text { (2013); Connell et al. } \\
\text { (2018) }\end{array}$ \\
\hline $\begin{array}{l}\text { Bile acid sequestrants } \\
\text { (FXR agonists) }\end{array}$ & Obeticholic acid, Tropifexor & $\begin{array}{l}\text { Obeticholic acid: U.S. FDA } \\
\text { approved for treating primary } \\
\text { biliary cholangitis Tropifexor: } \\
\text { showed clinical efficacy in phase } \\
2 \text { clinical trials composed of } \\
\text { patients with primary bile acid } \\
\text { diarrhea }\end{array}$ & $\begin{array}{l}\text { Inhibits hepatic bile acid } \\
\text { synthesis and improves the } \\
\text { stool index of patients with bile } \\
\text { acid-associated diarrhea }\end{array}$ & $\begin{array}{l}\text { IBS-D/ } \\
\text { functional } \\
\text { diarrhea }\end{array}$ & $\begin{array}{l}\text { Walters et al. (2015); } \\
\text { Camilleri et al. (2020b) }\end{array}$ \\
\hline $\begin{array}{l}\text { Bile acid transporter } \\
\text { inhibitor (IBAT antagonists) }\end{array}$ & Elobixibat & $\begin{array}{l}\text { Approved in Japan for treating } \\
\text { chronic constipation. Elobixibat } \\
\text { demonstrated clinical efficacy in } \\
\text { phase } 2 \text { clinical trials composed } \\
\text { of patients with chronic } \\
\text { constipation }\end{array}$ & $\begin{array}{l}\text { Efficacious treatment for } \\
\text { constipation, improves gut } \\
\text { transit and symptoms via } \\
\text { increasing colonic bile acids }\end{array}$ & $\begin{array}{l}\text { IBS-C/ } \\
\text { functional } \\
\text { constipation }\end{array}$ & $\begin{array}{l}\text { Vijayvargiya et al. } \\
(2018)\end{array}$ \\
\hline \multirow[t]{3}{*}{$\begin{array}{l}\text { Anti-inflammatory agents } \\
\text { (Mast cell stabilizer, } \\
\text { Histamine receptor-1 } \\
\text { antagonist) }\end{array}$} & Mesalazine & $\begin{array}{l}\text { Phase } 3 \text { clinical trial failed to show } \\
\text { any benefit in patients with IBS }\end{array}$ & $\begin{array}{l}\text { Sustains therapy response } \\
\text { and benefits for a subgroup of } \\
\text { patients with IBS in } \\
\text { maintaining gut immune } \\
\text { homeostasis }\end{array}$ & IBS & Barbara et al. (2016a) \\
\hline & Ketotifen & $\begin{array}{l}\text { A clinical trial (registration number } \\
\text { NTR39, ISRCTN22504486) in } \\
\text { the Netherlands showed } \\
\text { increased discomfort thresholds } \\
\text { to rectal distension, resulting in } \\
\text { improved abdominal pain in a } \\
\text { subset of IBS patients }\end{array}$ & $\begin{array}{l}\text { Reduces symptoms by } \\
\text { improving visceral pain } \\
\text { threshold levels in IBS patients }\end{array}$ & IBS & Klooker et al. (2010) \\
\hline & Ebastine & $\begin{array}{l}\text { Phase } 4 \text { clinical trials showed } \\
\text { clinical efficacy in patients } \\
\text { with IBS }\end{array}$ & $\begin{array}{l}\text { Reduces abdominal pain and } \\
\text { visceral hypersensitivity in } \\
\text { patients with IBS }\end{array}$ & IBS & Wouters et al. (2016a) \\
\hline $\begin{array}{l}\text { Neuromodulators (TCAs, } \\
\text { TeCAs, SSRIs, SNRIs) }\end{array}$ & Amitriptyline & $\begin{array}{l}\text { Phase } 2 \text { clinical trials showed } \\
\text { improvement of Gl symptoms } \\
\text { and sleep quality in patients with } \\
\text { FD. It reduces visceral }\end{array}$ & $\begin{array}{l}\text { Affects gastrointestinal motility } \\
\text { through anticholinergic and } \\
\text { serotonergic mechanisms. } \\
\text { TCAs reduce visceral } \\
\text { hypersensitivity. Anti- }\end{array}$ & $\mathrm{FD}, \mathrm{IBS}$ & Mertz et al. (1998) \\
\hline
\end{tabular}

(Continued on following page) 
TABLE 3 | (Continued) Currently available pharmacological agents for bowel disorders.

\begin{tabular}{|c|c|c|c|c|c|}
\hline \multicolumn{2}{|c|}{ Class/Drug name } & \multirow{2}{*}{$\begin{array}{l}\begin{array}{l}\text { Status (clinically approved/ } \\
\text { development/availability) }\end{array} \\
\text { hypersensitivity in patients } \\
\text { with IBS }\end{array}$} & \multirow{2}{*}{$\begin{array}{l}\text { Clinical outcome } \\
\text { depressant therapy may lead } \\
\text { to neurogenesis }\end{array}$} & \multirow{2}{*}{$\begin{array}{l}\text { Disease } \\
\text { condition }\end{array}$} & \multirow[t]{2}{*}{ References } \\
\hline & & & & & \\
\hline & Duloxetine & $\begin{array}{l}\text { Phase } 4 \text { clinical trials showed } \\
\text { clinical efficacy in patients } \\
\text { with IBS }\end{array}$ & $\begin{array}{l}\text { Improved Gl symptom } \\
\text { severity via indirectly treating } \\
\text { depressive symptoms }\end{array}$ & IBS & $\begin{array}{l}\text { Drossman et al. } \\
\text { (2018) } \\
\text { Tornblom and } \\
\text { Drossman, (2018) }\end{array}$ \\
\hline \multirow[t]{2}{*}{$\begin{array}{l}\text { Intestinal Secretagogues } \\
\text { (CCl2 agonists, Guanylate } \\
\text { cyclase-C receptor } \\
\text { agonists) }\end{array}$} & Lubiprostone & $\begin{array}{l}\text { U.S. FDA approved medicine for } \\
\text { treating patients with IBS-C and } \\
\text { chronic constipation and is also } \\
\text { approved for the treatment of } \\
\text { IBS-C and chronic constipation in } \\
\text { many other countries }\end{array}$ & $\begin{array}{l}\text { Increases fecal water content } \\
\text { by promoting fluid secretion } \\
\text { into the lumen }\end{array}$ & $\begin{array}{l}\text { IBS-C/ } \\
\text { functional } \\
\text { constipation }\end{array}$ & $\begin{array}{l}\text { Drossman et al. } \\
\text { (2009) }\end{array}$ \\
\hline & Linaclotide & $\begin{array}{l}\text { Approved in most parts of the } \\
\text { world for the treatment of IBS-C } \\
\text { and chronic constipation }\end{array}$ & $\begin{array}{l}\text { Increases water secretion via } \\
\text { targeting cGMP leading to the } \\
\text { secretion of bicarbonate and } \\
\text { chloride into the gut }\end{array}$ & $\begin{array}{l}\text { IBS-C/ } \\
\text { functional } \\
\text { constipation }\end{array}$ & Chey et al. (2012) \\
\hline \multirow[t]{2}{*}{$\begin{array}{l}\text { Visceral Analgesics } \\
\text { (Biased } \mu \text {-Opioid receptor } \\
\text { ligands, CB2R agonists) }\end{array}$} & Oliceridine & $\begin{array}{l}\text { U.S. FDA approved medicine for } \\
\text { managing moderate to severe } \\
\text { acute pain in adults. It has } \\
\text { comparable analgesic effects to } \\
\text { morphine, although human } \\
\text { studies are necessary to test the } \\
\text { efficacy for visceral pain } \\
\text { management in patients with IBS }\end{array}$ & $\begin{array}{l}\text { Manages severe and } \\
\text { moderate acute pain in adults } \\
\text { that were unable to be } \\
\text { successfully treated with other } \\
\text { medications (excluding } \\
\text { opioids) }\end{array}$ & IBS & $\begin{array}{l}\text { Markham (2020); } \\
\text { Camilleri (2021) }\end{array}$ \\
\hline & Olorinab & $\begin{array}{l}\text { Phase } 1 \text { clinical trials } \\
\text { demonstrated clinical efficacy in } \\
\text { IBS patients, likely due to its } \\
\text { potential analgesic effects }\end{array}$ & $\begin{array}{l}\text { Potential analgesic effects in } \\
\text { patients with IBS. More robust } \\
\text { studies are needed to test the } \\
\text { efficacy }\end{array}$ & IBS & Castro et al. (2021) \\
\hline
\end{tabular}

Abbreviations: 5-HT3R: 5-hydroxytryptamine receptor 3, cGMP: cyclic guanosine monophosphate, GCSI: gastroparesis cardinal symptom index, IBS-D: diarrhea-predominant IBS, CB2R: cannabinoid type 2 receptor, FGF-19: fibroblast growth factor 19, SNRIs: serotonin noradrenaline reuptake inhibitors, TCAs: tricyclic anti-depressants, CCI2: chloride channel 2, TeCAs: tetracyclic anti-depressants, IBAT: ileal bile acid transporter, SIBO: small intestinal bacterial overgrowth, SSRIs: selective serotonin reuptake inhibitors, IBS-C: constipationpredominant IBS.

\section{5-HT3R Antagonists}

Alosetron (FDA approved medicine), ramosetron [ClinicalTrials.gov: NCT01225237 (phase 4)], and ondansetron [ClinicalTrails.gov: NCT03555188 (phase 3)], 5-HT3R antagonists, have been demonstrated to effectively treat IBS-D patients (Simren and Tack, 2018). Among 18 randomized controlled trials 5-HT3R antagonists were the best at improving stool consistency and symptoms of IBS-D, such as abdominal pain (Rokkas et al., 2021).

\section{PROBIOTICS AND ANTIBIOTICS}

Rifaximin (approved in most parts of the world for the treatment of IBS) was studied in randomized trials involving 1,260 patients with IBS (Pimentel et al., 2011). It was demonstrated to improve overall symptoms and bloating when compared to the placebo group. A study on FD patients also showed the efficacy of rifaximin, which was tolerated well and provided adequate relief of dyspeptic symptoms when compared to placebo treated patients (Tan et al., 2017).

Adults experiencing upper GI symptoms who ingested fermented milk with or without Bifidobacterium bifidum YIT10347 daily had improved abdominal discomfort and epigastric pain (Gomi et al., 2018). Another interventional study with Lactobacillus gasseri OLL2716 or placebo on FD patients showed symptom improvement in the treated group (Koga et al., 2019). Bifidobacterium infantis 35,624 has been found to normalize bowel movements and improve overall symptoms in all IBS subtypes (Charbonneau et al., 2013). Bifidobacterium lactis DN-173010 and VSL\#3 probiotics are effective in treating flatulence, distention, and bloating (Aragon et al., 2010; Connell et al., 2018).

\section{BILE ACID SEQUESTRANTS}

Adults with symptoms characteristic of IBS-D and functional diarrhea were shown to have an overrepresentation of increased fecal BA excretion (Vijayvargiya and Camilleri, 2019; Mars et al., 2020). Obeticholic acid stimulates fibroblast growth factor 19 and results in a reduction of colonic BA concentration, therefore rescuing diarrhea (Walters et al., 2015). Moreover, Tropifexor slowed colonic emptying and improved the stool index of patients with BA-associated diarrhea (Camilleri et al., 2020b). Finally, an additional FXR agonist, obeticholic acid got US. FDA approval for treating primary biliary cholangitis (Walters et al., 2015; Camilleri et al., 2020b; Bowlus et al., 2020). 


\section{BILE ACID TRANSPORTER INHIBITOR}

Elobixibat, an IBAT inhibitor, improves colonic motility in patients with IBS-C and functional constipation (Chey et al., 2011; Vijayvargiya et al., 2018; Khanna and Camilleri, 2021).

\section{ANTI-INFLAMMATORY AGENTS}

The occurrence of visceral hypersensitivity in some patients with IBS and has been associated with the release of tryptase and histamine, mucosal mast cell activation (Matricon et al., 2012; AguileraLizarraga et al., 2021) Ketotifen improved the visceral pain threshold and reduced abdominal pain in IBS patients with visceral hypersensitivity (Klooker et al., 2010). Another study showed that the HRH1 antagonist, ebastine, reduced visceral hypersensitivity, and further, patients also experience symptom relief when compared to the placebo group (Wouters et al., 2016a).

\section{INTESTINAL SECRETAGOGUES}

Intestinal secretagogues, Lubiprostone and linaclotide (approved medicine for treating patients with IBS-C and chronic constipation and is also approved for the treatment of IBS-C and chronic constipation in many other countries) demonstrated exceptional efficacy in patients with IBS-C and functional constipation (Pannemans and Tack, 2018). Lubiprostone increases the amount of fluid secretion into the gut through bicarbonate and chloride secretion by acting on intestinal enterocytes $\mathrm{ClC} 2$, which leads to accelerated gut transit and improved stool consistency (Johanson et al., 2008; Drossman et al., 2009; Black et al., 2018). Linaclotide accelerates gut transit and inhibits visceral hypersensitivity by acting on the GC-C receptor on enterocytes (Chey et al., 2012; Rao et al., 2012; Black et al., 2018).

\section{VISCERAL ANALGESICS}

The GI tract contains a plethora of opioid receptors, and drugs target these receptors to reduce the perception of pain and slow gut transit (Raehal et al., 2011). Analgesia is induced through G protein-mediated pathway activation or $\beta$-arrestin activation when opioids bind to $\mu$-opioid receptors, which depresses central nervous system functions (e.g., respiration and cognition) and delays gut motility (Raehal et al., 2011). Biased $\mu$-opioid receptor ligands can improve gut function and analgesia by solely activating the $G$ protein pathway (Camilleri, 2021). The biased $\mu$-opioid receptor ligand, oliceridine, has comparable analgesic effects to morphine, although human studies are necessary to test the efficacy for visceral pain management (Singla et al., 2019; Markham, 2020). Olorinab is a CB2 agonist that alters immune function and visceral sensation in a rodent model of colitis and might modulate gut motility in patients with IBS (Castro et al., 2021). In the future, human studies are warranted to test these medications in treating visceral pain in patients with FGIDs and gut motility disorders.

\section{CENTRAL NEUROMODULATORS}

Central neuromodulators are increasingly used for the treatment of FGIDs (Drossman et al., 2018). One study on patients with FD showed amitriptyline [ClinicalTrilas.gov: NCT00248651 (phase 2)], a TCA, improved GI symptoms and modestly improved sleep quality (Mertz et al., 1998; Herrick et al., 2018). TCAs were more efficacious in 11 randomized trials involving 744 patients with chronic constipation and IBS-C when compared to the placebo group (Ford et al., 2014). TCAs are first-line central neuromodulators that can be used to treat IBS, particularly IBSD. Further, poor sleep and diarrhea were improved following treatment with the TCAs (imipramine and amitriptyline) (Rahimi et al., 2009). The SSRI [Citalopram, ClinicalTrials.gov: NCT00477165 (phase 2)] and SNRI [duloxetine, ClinicalTrials.gov: NCT00401258 (phase 4); or milnacipran, Clinicaltrials. gov: NCT01471379 (phase 2)] class of medications can reduce pain in patients with IBS (Brennan et al., 2009; Tornblom and Drossman, 2018). In addition, they have fewer side effects than TCAs; however, more robust studies are warranted to elucidate the effects of these medications in patients with IBS.

\section{CONCLUSION AND FUTURE DIRECTIONS}

An enhanced understanding of the physiological and pathophysiological mechanisms underlying functional and motility GI disorders has ushered in the development of novel treatment approaches in the clinical care of patients. Pharmacological agents that are developed based on the cellular and molecular mechanisms underlying pathologies of these disorders provide the best avenue for future pharmaceutical development. Additionally, currently available therapies lack long-term effectiveness and safety and have poorly understood mechanisms of action for their use to treat motility disorders and FGIDs. The heterogeneous nature, the poor correlation between improved gut functions and symptoms, and the absence of a single unifying target mechanism are hurdles to developing new therapeutic options.

The collaborative work between gastroenterologists, microbiologists, neurologists, epidemiologists, and bioinformaticians may lead to thrilling discoveries in the field of FGIDs. Further, the enhanced understanding of host-gut microbial crosstalk will allow better diagnostics and treatment options for patients with these disorders. Due to substantial clinical overlap between these disorders and the sharing of symptoms and pathophysiological mechanisms between different anatomical GI regions, a combination of symptoms along with testing for the underlying cellular and molecular pathologies might help physicians stratify subsets of patients that can be more effectively treated using specific medications.

An innovative approach that uses longitudinal and multicentric studies aims to fill current knowledge gaps and characterize the patients precisely based on multi-omics data profiling from the host 
epigenome, transcriptome, dietary profiles, metabolome, and gut microbiome, allowing for more effective treatment of these patients. More targeted approaches will help to relieve symptoms and restore gut-brain homeostasis in patients while enhancing the stratification of therapeutic modalities for gut motility disorders and FGIDs.

\section{REFERENCES}

Acosta, A., and Camilleri, M. (2015). Prokinetics in Gastroparesis. Gastroenterol. Clin. North. Am. 44 (1), 97-111. doi:10.1016/j.gtc.2014.11.008

Aguilera-Lizarraga, J., Florens, M. V., Viola, M. F., Jain, P., Decraecker, L., Appeltans, I., et al. (2021). Local Immune Response to Food Antigens Drives Meal-Induced Abdominal Pain. Nature 590 (7844), 151-156. doi:10.1038/s41586-020-03118-2

Akbar, A., Yiangou, Y., Facer, P., Walters, J. R., Anand, P., and Ghosh, S. (2008). Increased Capsaicin Receptor TRPV1-Expressing Sensory Fibres in Irritable Bowel Syndrome and Their Correlation with Abdominal Pain. Gut 57 (7), 923-929. doi:10.1136/gut.2007.138982

Altan, E., Masaoka, T., Farré, R., and Tack, J. (2012). Acotiamide, a Novel Gastroprokinetic for the Treatment of Patients with Functional Dyspepsia: Postprandial Distress Syndrome. Expert Rev. Gastroenterol. Hepatol. 6 (5), 533-544. doi:10.1586/egh.12.34

Aragon, G., Graham, D. B., Borum, M., and Doman, D. B. (2010). Probiotic Therapy for Irritable Bowel Syndrome. Gastroenterol. Hepatol. (N Y) 6 (1), $39-44$.

Asano, H., Tomita, T., Nakamura, K., Yamasaki, T., Okugawa, T., Kondo, T., et al. (2017). Prevalence of Gastric Motility Disorders in Patients with Functional Dyspepsia. J. Neurogastroenterol Motil. 23 (3), 392-399. doi:10.5056/jnm16173

Bäckhed, F., Ley, R. E., Sonnenburg, J. L., Peterson, D. A., and Gordon, J. I. (2005). Host-bacterial Mutualism in the Human Intestine. Science 307 (5717), 1915-1920. doi:10.1126/science.1104816

Barbara, G., Cremon, C., Annese, V., Basilisco, G., Bazzoli, F., Bellini, M., et al. (2016a). Randomised Controlled Trial of Mesalazine in IBS. Gut 65 (1), 82-90. doi:10.1136/gutjnl-2014-308188

Barbara, G., Cremon, C., Carini, G., Bellacosa, L., Zecchi, L., De Giorgio, R., et al. (2011). The Immune System in Irritable Bowel Syndrome. J. Neurogastroenterol Motil. 17 (4), 349-359. doi:10.5056/jnm.2011.17.4.349

Barbara, G., Stanghellini, V., De Giorgio, R., Cremon, C., Cottrell, G. S., Santini, D., et al. (2004). Activated Mast Cells in Proximity to Colonic Nerves Correlate with Abdominal Pain in Irritable Bowel Syndrome. Gastroenterology 126 (3), 693-702. doi:10.1053/j.gastro.2003.11.055

Barbara, G., Wang, B., Stanghellini, V., de Giorgio, R., Cremon, C., Di Nardo, G., et al. (2007). Mast Cell-dependent Excitation of Visceral-Nociceptive Sensory Neurons in Irritable Bowel Syndrome. Gastroenterology 132 (1), 26-37. doi:10.1053/j.gastro.2006.11.039

Barbara, G., Feinle-Bisset, C., Ghoshal, U. C., Santos, J., Vanner, S. J., Vergnolle, N., et al. (2016b). The Intestinal Microenvironment and Functional Gastrointestinal Disorders. Gastroenterology 150, 1305-1318. doi:10.1053/ j.gastro.2016.02.028

Bellono, N. W., Bayrer, J. R., Leitch, D. B., Castro, J., Zhang, C., O'Donnell, T. A., et al. (2017). Enterochromaffin Cells Are Gut Chemosensors that Couple to Sensory Neural Pathways. Cell 170 (1), 185-e16. e116. doi:10.1016/ j.cell.2017.05.034

Bertiaux-Vandaële, N., Youmba, S. B., Belmonte, L., Lecleire, S., Antonietti, M., Gourcerol, G., et al. (2011). The Expression and the Cellular Distribution of the Tight junction Proteins Are Altered in Irritable Bowel Syndrome Patients with Differences According to the Disease Subtype. Am. J. Gastroenterol. 106 (12), 2165-2173. doi:10.1038/ajg.2011.257

Bharucha, A. E., Daley, S. L., Low, P. A., Gibbons, S. J., Choi, K. M., Camilleri, M., et al. (2016). Effects of Hemin on Heme Oxygenase-1, Gastric Emptying, and Symptoms in Diabetic Gastroparesis. Neurogastroenterol Motil. 28 (11), 1731-1740. doi:10.1111/nmo.12874

Bhattarai, Y., Williams, B. B., Battaglioli, E. J., Whitaker, W. R., Till, L., Grover, M., et al. (2018). Gut Microbiota-Produced Tryptamine Activates an Epithelial

\section{AUTHOR CONTRIBUTIONS}

RS and HZ reviewed the literature and drafted the original manuscript. SR and UG revised the manuscript critically and provided important intellectual directives. RS and $\mathrm{HZ}$ contributed equally as co-first authors to this study.

G-Protein-Coupled Receptor to Increase Colonic Secretion. Cell Host Microbe 23 (6), 775-e5. doi:10.1016/j.chom.2018.05.004

Bischoff, S. C., Barbara, G., Buurman, W., Ockhuizen, T., Schulzke, J. D., Serino, M., et al. (2014). Intestinal Permeability-Aa New Target for Disease Prevention and Therapy. BMC Gastroenterol. 14, 189. doi:10.1186/s12876-014-0189-7

Black, C. J., Burr, N. E., and Ford, A. C. (2020a). Relative Efficacy of Tegaserod in a Systematic Review and Network Meta-Analysis of Licensed Therapies for Irritable Bowel Syndrome with Constipation. Clin. Gastroenterol. Hepatol. 18 (5), 1238-e1. e1231. doi:10.1016/j.cgh.2019.07.007

Black, C. J., Burr, N. E., Quigley, E. M. M., Moayyedi, P., Houghton, L. A., and Ford, A. C. (2018). Efficacy of Secretagogues in Patients with Irritable Bowel Syndrome with Constipation: Systematic Review and Network Meta-Analysis. Gastroenterology 155 (6), 1753-1763. doi:10.1053/j.gastro.2018.08.021

Black, C. J., Drossman, D. A., Talley, N. J., Ruddy, J., and Ford, A. C. (2020b). Functional Gastrointestinal Disorders: Advances in Understanding and Management. Lancet 396 (10263), 1664-1674. doi:10.1016/S0140-6736(20) 32115-2

Black, C. J., and Ford, A. C. (2020). Global burden of Irritable Bowel Syndrome: Trends, Predictions and Risk Factors. Nat. Rev. Gastroenterol. Hepatol. 17 (8), 473-486. doi:10.1038/s41575-020-0286-8

Bowlus, C. L., Pockros, P. J., Kremer, A. E., Parés, A., Forman, L. M., Drenth, J. P. H., et al. (2020). Long-Term Obeticholic Acid Therapy Improves Histological Endpoints in Patients with Primary Biliary Cholangitis. Clin. Gastroenterol. Hepatol. 18 (5), 1170-e6. e1176. doi:10.1016/j.cgh.2019.09.050

Brancale, A., Shailubhai, K., Ferla, S., Ricci, A., Bassetto, M., and Jacob, G. S. (2017). Therapeutically Targeting Guanylate Cyclase-C: Computational Modeling of Plecanatide, a Uroguanylin Analog. Pharmacol. Res. Perspect. 5 (2), e00295. doi:10.1002/prp2.295

Brennan, B. P., Fogarty, K. V., Roberts, J. L., Reynolds, K. A., Pope, H. G., Jr., and Hudson, J. I. (2009). Duloxetine in the Treatment of Irritable Bowel Syndrome: an Open-Label Pilot Study. Hum. Psychopharmacol. 24 (5), 423-428. doi:10.1002/hup.1038

Bruley Des Varannes, S., Fléjou, J. F., Colin, R., Zaïm, M., Meunier, A., and BidautMazel, C. (2001). There Are Some Benefits for Eradicating Helicobacter pylori in Patients with Non-ulcer Dyspepsia. Aliment. Pharmacol. Ther. 15 (8), 1177-1185. doi:10.1046/j.1365-2036.2001.01014.x

Camilleri, M., and Atieh, J. (2021). New Developments in Prokinetic Therapy for Gastric Motility Disorders. Front. Pharmacol. 12, 711500. doi:10.3389/ fphar.2021.711500

Camilleri, M., Chedid, V., Ford, A. C., Haruma, K., Horowitz, M., Jones, K. L., et al. (2018). Gastroparesis. Nat. Rev. Dis. Primers 4 (1), 41. doi:10.1038/s41572-0180038-z

Camilleri, M., Kerstens, R., Rykx, A., and Vandeplassche, L. (2008). A PlaceboControlled Trial of Prucalopride for Severe Chronic Constipation. N. Engl. J. Med. 358 (22), 2344-2354. doi:10.1056/NEJMoa0800670

Camilleri, M. (2019). Leaky Gut: Mechanisms, Measurement and Clinical Implications in Humans. Gut 68 (8), 1516-1526. doi:10.1136/gutjnl-2019318427

Camilleri, M., Lembo, A., McCallum, R., Tourkodimitris, S., Kemps, L., Miller, M. B., et al. (2020a). Overall Safety of Relamorelin in Adults with Diabetic Gastroparesis: Analysis of Phase 2a and 2b Trial Data. Aliment. Pharmacol. Ther. 51 (11), 1139-1148. doi:10.1111/apt.15711

Camilleri, M., Madsen, K., Spiller, R., Greenwood-Van Meerveld, B., Van Meerveld, B. G., and Verne, G. N. (2012). Intestinal Barrier Function in Health and Gastrointestinal Disease. Neurogastroenterol Motil. 24 (6), 503-512. doi:10.1111/j.1365-2982.2012.01921.x

Camilleri, M. (2021). New Drugs on the Horizon for Functional and Motility Gastrointestinal Disorders. Gastroenterology 161 (3), 761-764. doi:10.1053/ j.gastro.2021.04.079 
Camilleri, M., Nord, S. L., Burton, D., Oduyebo, I., Zhang, Y., Chen, J., et al. (2020b). Randomised Clinical Trial: Significant Biochemical and Colonic Transit Effects of the Farnesoid X Receptor Agonist Tropifexor in Patients with Primary Bile Acid Diarrhoea. Aliment. Pharmacol. Ther. 52 (5), 808-820. doi:10.1111/apt.15967

Camilleri, M., and Sanders, K. M. (2022). Gastroparesis. Gastroenterology 162 (1), 68-e1. doi:10.1053/j.gastro.2021.10.028

Camilleri, M., and Stanghellini, V. (2013). Current Management Strategies and Emerging Treatments for Functional Dyspepsia. Nat. Rev. Gastroenterol. Hepatol. 10 (3), 187-194. doi:10.1038/nrgastro.2013.11

Cani, P. D. (2017). Gut Microbiota - at the Intersection of Everything? Nat. Rev. Gastroenterol. Hepatol. 14 (6), 321-322. doi:10.1038/ nrgastro.2017.54

Carabotti, M., Scirocco, A., Maselli, M. A., and Severi, C. (2015). The Gut-Brain axis: Interactions between Enteric Microbiota, central and Enteric Nervous Systems. Ann. Gastroenterol. 28 (2), 203-209.

Carbone, F., Van den Houte, K., Clevers, E., Andrews, C. N., Papathanasopoulos, A., Holvoet, L., et al. (2019). Prucalopride in Gastroparesis: A Randomized Placebo-Controlled Crossover Study. Am. J. Gastroenterol. 114 (8), 1265-1274. doi:10.14309/ajg.0000000000000304

Carlin, J. L., Lieberman, V. R., Dahal, A., Keefe, M. S., Xiao, C., Birznieks, G., et al. (2021). Efficacy and Safety of Tradipitant in Patients with Diabetic and Idiopathic Gastroparesis in a Randomized, PlaceboControlled Trial. Gastroenterology 160 (1), 76-e4. doi:10.1053/ j.gastro.2020.07.029

Castro, J., Garcia-Caraballo, S., Maddern, J., Schober, G., Lumsden, A., Harrington, A., et al. (2021). Olorinab (APD371), a Peripherally Acting, Highly Selective, Full Agonist of the Cannabinoid Receptor 2, Reduces Colitis-Induced Acute and Chronic Visceral Hypersensitivity in Rodents. Pain 163, e72-e86. doi:10.1097/j.pain.0000000000002314

Charbonneau, D., Gibb, R. D., and Quigley, E. M. (2013). Fecal Excretion of Bifidobacterium Infantis 35624 and Changes in Fecal Microbiota after Eight Weeks of Oral Supplementation with Encapsulated Probiotic. Gut Microbes 4 (3), 201-211. doi:10.4161/gmic.24196

Chedid, V., Brandler, J., Arndt, K., Vijayvargiya, P., Wang, X. J., Burton, D., et al. (2021). Randomised Study: Effects of the 5-HT4 Receptor Agonist Felcisetrag vs Placebo on Gut Transit in Patients with Gastroparesis. Aliment. Pharmacol. Ther. 53 (9), 1010-1020. doi:10.1111/apt.16304

Chedid, V., and Camilleri, M. (2017). Relamorelin for the Treatment of Gastrointestinal Motility Disorders. Expert Opin. Investig. Drugs 26 (10), 1189-1197. doi:10.1080/13543784.2017.1373088

Chey, W. D., Camilleri, M., Chang, L., Rikner, L., and Graffner, H. (2011). A Randomized Placebo-Controlled Phase IIb Trial of A3309, a Bile Acid Transporter Inhibitor, for Chronic Idiopathic Constipation. Am. J. Gastroenterol. 106 (10), 1803-1812. doi:10.1038/ajg.2011.162

Chey, W. D., Lembo, A. J., Lavins, B. J., Shiff, S. J., Kurtz, C. B., Currie, M. G., et al. (2012). Linaclotide for Irritable Bowel Syndrome with Constipation: a 26-week, Randomized, Double-Blind, Placebo-Controlled Trial to Evaluate Efficacy and Safety. Am. J. Gastroenterol. 107 (11), 1702-1712. doi:10.1038/ajg.2012.254

Choi, K. M., Kashyap, P. C., Dutta, N., Stoltz, G. J., Ordog, T., Shea Donohue, T., et al. (2010). CD206-positive M2 Macrophages that Express Heme Oxygenase-1 Protect against Diabetic Gastroparesis in Mice. Gastroenterology 138 (7), 23992409e2391-e1. doi:10.1053/j.gastro.2010.02.014

Cipriani, G., Gibbons, S. J., Kashyap, P. C., and Farrugia, G. (2016). Intrinsic Gastrointestinal Macrophages: Their Phenotype and Role in Gastrointestinal Motility. Cell Mol Gastroenterol Hepatol 2 (2), 120-e1. e121. doi:10.1016/ j.jcmgh.2016.01.003

Connell, M., Shin, A., James-Stevenson, T., Xu, H., Imperiale, T. F., and Herron, J. (2018). Systematic Review and Meta-Analysis: Efficacy of Patented Probiotic, VSL\#3, in Irritable Bowel Syndrome. Neurogastroenterol Motil. 30 (12), e13427. doi:10.1111/nmo.13427

Desai, M. S., Seekatz, A. M., Koropatkin, N. M., Kamada, N., Hickey, C. A., Wolter, M., et al. (2016). A Dietary Fiber-Deprived Gut Microbiota Degrades the Colonic Mucus Barrier and Enhances Pathogen Susceptibility. Cell 167 (5), 1339-e21. e1321. doi:10.1016/j.cell.2016.10.043

Dothel, G., Barbaro, M. R., Boudin, H., Vasina, V., Cremon, C., Gargano, L., et al. (2015). Nerve Fiber Outgrowth Is Increased in the Intestinal Mucosa of Patients with Irritable Bowel Syndrome. Gastroenterology 148 (5), 1002-e4. e1004. doi:10.1053/j.gastro.2015.01.042

Drossman, D. A., Chey, W. D., Johanson, J. F., Fass, R., Scott, C., Panas, R., et al. (2009). Clinical Trial: Lubiprostone in Patients with Constipation-Associated Irritable Bowel Syndrome-Rresults of Two Randomized, Placebo-Controlled Studies. Aliment. Pharmacol. Ther. 29 (3), 329-341. doi:10.1111/j.13652036.2008.03881.x

Drossman, D. A. (2016). Functional Gastrointestinal Disorders: History, Pathophysiology, Clinical Features and Rome IV. Gastroenterology S00165085 (16), 00223-00227. doi:10.1053/j.gastro.2016.02.032

Drossman, D. A., Tack, J., Ford, A. C., Szigethy, E., Törnblom, H., and Van Oudenhove, L. (2018). Neuromodulators for Functional Gastrointestinal Disorders (Disorders of Gut-Brain Interaction): A Rome Foundation Working Team Report. Gastroenterology 154 (4), 1140-e1. e1141. doi:10.1053/j.gastro.2017.11.279

Du, L. J., Chen, B. R., Kim, J. J., Kim, S., Shen, J. H., and Dai, N. (2016). Helicobacter pylori Eradication Therapy for Functional Dyspepsia: Systematic Review and Meta-Analysis. World J. Gastroenterol. 22 (12), 3486-3495. doi:10.3748/ wjg.v22.i12.3486

Dumitrascu, D. L., and Weinbeck, M. (2000). Domperidone versus Metoclopramide in the Treatment of Diabetic Gastroparesis. Am. J. Gastroenterol. 95 (1), 316-317. doi:10.1111/j.1572-0241.2000.01721.x

El-Salhy, M., Hatlebakk, J. G., Gilja, O. H., Bråthen Kristoffersen, A., and Hausken, T. (2020). Efficacy of Faecal Microbiota Transplantation for Patients with Irritable Bowel Syndrome in a Randomised, Double-Blind, Placebo-Controlled Study. Gut 69 (5), 859-867. doi:10.1136/gutjnl-2019-319630

El-Salhy, M., Patcharatrakul, T., and Gonlachanvit, S. (2021). The Role of Diet in the Pathophysiology and Management of Irritable Bowel Syndrome. Indian J. Gastroenterol. 40 (2), 111-119. doi:10.1007/s12664-020-01144-6

Enck, P., Aziz, Q., Barbara, G., Farmer, A. D., Fukudo, S., Mayer, E. A., et al. (2016). Irritable Bowel Syndrome. Nat. Rev. Dis. Primers 2, 16014. doi:10.1038/ nrdp.2016.14

Enck, P., Azpiroz, F., Boeckxstaens, G., Elsenbruch, S., Feinle-Bisset, C., Holtmann, G., et al. (2017). Functional Dyspepsia. Nat. Rev. Dis. Primers 3, 17081. doi:10.1038/nrdp.2017.81

Farzaei, M. H., Bahramsoltani, R., Abdollahi, M., and Rahimi, R. (2016). The Role of Visceral Hypersensitivity in Irritable Bowel Syndrome: Pharmacological Targets and Novel Treatments. J. Neurogastroenterol Motil. 22 (4), 558-574. doi:10.5056/jnm16001

Ford, A. C., Mahadeva, S., Carbone, M. F., Lacy, B. E., and Talley, N. J. (2020). Functional Dyspepsia. Lancet 396 (10263), 1689-1702. doi:10.1016/S01406736(20)30469-4

Ford, A. C., Moayyedi, P., Lacy, B. E., Lembo, A. J., Saito, Y. A., Schiller, L. R., et al. (2014). American College of Gastroenterology Monograph on the Management of Irritable Bowel Syndrome and Chronic Idiopathic Constipation. Am. J. Gastroenterol. 109 (Suppl. 1), S2-S26. doi:10.1038/ajg.2014.187

Fritscher-Ravens, A., Schuppan, D., Ellrichmann, M., Schoch, S., Röcken, C., Brasch, J., et al. (2014). Confocal Endomicroscopy Shows Food-Associated Changes in the Intestinal Mucosa of Patients with Irritable Bowel Syndrome. Gastroenterology 147 (5), 1012-e4. e1014. doi:10.1053/j.gastro.2014.07.046

Gatta, L., and Scarpignato, C. (2017). Systematic Review with Meta-Analysis: Rifaximin Is Effective and Safe for the Treatment of Small Intestine Bacterial Overgrowth. Aliment. Pharmacol. Ther. 45 (5), 604-616. doi:10.1111/apt.13928

Ghoshal, U. C., Bhut, B., and Misra, A. (2021). Patients with Specific Gastrointestinal Motility Disorders Are Commonly Diagnosed as Functional GI Disorders in the Early Stage by Community Physicians Due to Lack of Awareness. Turk J. Gastroenterol. 32 (4), 336-348. doi:10.5152/tjg.2021.20514

Ghoshal, U. C. (2020). Marshall and Warren Lecture 2019: A Paradigm Shift in Pathophysiological Basis of Irritable Bowel Syndrome and its Implication on Treatment. J. Gastroenterol. Hepatol. 35 (5), 712-721. doi:10.1111/jgh.15032

Ghoshal, U. C., Singh, R., Chang, F. Y., Hou, X., Wong, B. C., Kachintorn, U., et al. (2011a). Epidemiology of Uninvestigated and Functional Dyspepsia in Asia: Facts and Fiction. J. Neurogastroenterol Motil. 17 (3), 235-244. doi:10.5056/ jnm.2011.17.3.235

Ghoshal, U. C., and Singh, R. (2017). Frequency and Risk Factors of Functional Gastro-Intestinal Disorders in a Rural Indian Population. J. Gastroenterol. Hepatol. 32 (2), 378-387. doi:10.1111/jgh.13465 
Ghoshal, U. C., and Singh, R. (2014). Pathogenesis of Irritable Bowel Syndrome: Is it Really in the Gene? J. Neurogastroenterol Motil. 20 (3), 284-286. doi:10.5056/ jnm14071

Ghoshal, U. C., Srivastava, D., and Misra, A. (2018). A Randomized Double-Blind Placebo-Controlled Trial Showing Rifaximin to Improve Constipation by Reducing Methane Production and Accelerating colon Transit: A Pilot Study. Indian J. Gastroenterol. 37 (5), 416-423. doi:10.1007/s12664-0180901-6

Ghoshal, U. C., Srivastava, D., Verma, A., and Misra, A. (2011b). Slow Transit Constipation Associated with Excess Methane Production and its Improvement Following Rifaximin Therapy: a Case Report. J. Neurogastroenterol Motil. 17 (2), 185-188. doi:10.5056/jnm.2011.17.2.185

Gomi, A., Yamaji, K., Watanabe, O., Yoshioka, M., Miyazaki, K., Iwama, Y., et al. (2018). Bifidobacterium Bifidum YIT 10347 Fermented Milk Exerts Beneficial Effects on Gastrointestinal Discomfort and Symptoms in Healthy Adults: A Double-Blind, Randomized, Placebo-Controlled Study. J. Dairy Sci. 101 (6), 4830-4841. doi:10.3168/jds.2017-13803

Gottfried-Blackmore, A., Namkoong, H., Adler, E., Martin, B., Gubatan, J., Fernandez-Becker, N., et al. (2021). Gastric Mucosal Immune Profiling and Dysregulation in Idiopathic Gastroparesis. Clin. Transl Gastroenterol. 12 (5), e00349. doi:10.14309/ctg.0000000000000349

Grover, M., Berumen, A., Peters, S., Wei, T., Breen-Lyles, M., Harmsen, W. S., et al. (2021). Intestinal Chemosensitivity in Irritable Bowel Syndrome Associates with Small Intestinal TRPV Channel Expression. Aliment. Pharmacol. Ther. 54 (9), 1179-1192. doi:10.1111/apt.16591

Grover, M., Farrugia, G., Lurken, M. S., Bernard, C. E., Faussone-Pellegrini, M. S., Smyrk, T. C., et al. (2011). Cellular Changes in Diabetic and Idiopathic Gastroparesis. Gastroenterology 140 (5), 1575-e8. doi:10.1053/j.gastro.2011.01.046

Grover, M., Farrugia, G., and Stanghellini, V. (2019). Gastroparesis: a Turning point in Understanding and Treatment. Gut 68 (12), 2238-2250. doi:10.1136/ gutjnl-2019-318712

Grover, M., Gibbons, S. J., Nair, A. A., Bernard, C. E., Zubair, A. S., Eisenman, S. T., et al. (2018). Transcriptomic Signatures Reveal Immune Dysregulation in Human Diabetic and Idiopathic Gastroparesis. BMC Med. Genomics 11 (1), 62. doi:10.1186/s12920-018-0379-1

Guleria, A., Karyampudi, A., Singh, R., Khetrapal, C. L., Verma, A., Ghoshal, U. C., et al. (2017). Mapping of Brain Activations to Rectal Balloon Distension Stimuli in Male Patients with Irritable Bowel Syndrome Using Functional Magnetic Resonance Imaging. J. Neurogastroenterol Motil. 23 (3), 415-427. doi:10.5056/ jnm16148

Herrick, L. M., Camilleri, M., Schleck, C. D., Zinsmeister, A. R., Saito, Y. A., and Talley, N. J. (2018). Effects of Amitriptyline and Escitalopram on Sleep and Mood in Patients with Functional Dyspepsia. Clin. Gastroenterol. Hepatol. 16 (3), 401-e2. e402. doi:10.1016/j.cgh.2017.10.021

Ianiro, G., Eusebi, L. H., Black, C. J., Gasbarrini, A., Cammarota, G., and Ford, A. C. (2019). Systematic Review with Meta-Analysis: Efficacy of Faecal Microbiota Transplantation for the Treatment of Irritable Bowel Syndrome. Aliment. Pharmacol. Ther. 50 (3), 240-248. doi:10.1111/apt.15330

Iovino, P., Bucci, C., Tremolaterra, F., Santonicola, A., and Chiarioni, G. (2014). Bloating and Functional Gastro-Intestinal Disorders: where Are We and where Are We Going? World J. Gastroenterol. 20 (39), 14407-14419. doi:10.3748/ wjg.v20.i39.14407

Islam, B. N., Sharman, S. K., and Browning, D. D. (2018). Clinical Utility of Plecanatide in the Treatment of Chronic Idiopathic Constipation. Int. J. Gen. Med. 11, 323-330. doi:10.2147/IJGM.S125051

Jacob, D., Busciglio, I., Burton, D., Halawi, H., Oduyebo, I., Rhoten, D., et al. (2017). Effects of NK1 Receptors on Gastric Motor Functions and Satiation in Healthy Humans: Results from a Controlled Trial with the NK1 Antagonist Aprepitant. Am. J. Physiol. Gastrointest. Liver Physiol. 313 (5), G505-G510. doi:10.1152/ ajpgi.00197.2017

Ji, S., Traini, C., Mischopoulou, M., Gibbons, S. J., Ligresti, G., Faussone-Pellegrini, M. S., et al. (2021). Muscularis Macrophages Establish Cell-To-Cell Contacts with telocytes/PDGFR $\alpha$-Positive Cells and Smooth Muscle Cells in the Human and Mouse Gastrointestinal Tract. Neurogastroenterol Motil. 33 (3), e13993. doi:10.1111/nmo.13993

Jiang, C., Xu, Q., Wen, X., and Sun, H. (2015). Current Developments in Pharmacological Therapeutics for Chronic Constipation. Acta Pharm. Sin B 5 (4), 300-309. doi:10.1016/j.apsb.2015.05.006
Jin, B., Ha, S. E., Wei, L., Singh, R., Zogg, H., Clemmensen, B., et al. (2021). Colonic Motility Is Improved by the Activation of 5-HT2B Receptors on Interstitial Cells of Cajal in Diabetic Mice. Gastroenterology 161 (2), 608-e7. e607. doi:10.1053/j.gastro.2021.04.040

Johanson, J. F., Morton, D., Geenen, J., and Ueno, R. (2008). Multicenter, 4-week, Double-Blind, Randomized, Placebo-Controlled Trial of Lubiprostone, a Locally-Acting Type-2 Chloride Channel Activator, in Patients with Chronic Constipation. Am. J. Gastroenterol. 103 (1), 170-177. doi:10.1111/j.15720241.2007.01524.x

Johanson, J. F., Wald, A., Tougas, G., Chey, W. D., Novick, J. S., Lembo, A. J., et al. (2004). Effect of Tegaserod in Chronic Constipation: a Randomized, DoubleBlind, Controlled Trial. Clin. Gastroenterol. Hepatol. 2 (9), 796-805. doi:10.1016/s1542-3565(04)00356-8

Khanna, L., and Camilleri, M. (2021). Review Article: Elobixibat: a Novel Treatment for Chronic Constipation. Aliment. Pharmacol. Ther. 53 (2), 234-242. doi:10.1111/apt.16143

Khoruts, A., and Sadowsky, M. J. (2016). Understanding the Mechanisms of Faecal Microbiota Transplantation. Nat. Rev. Gastroenterol. Hepatol. 13 (9), 508-516. doi:10.1038/nrgastro.2016.98

Kim, S. E., Park, Y. S., Kim, N., Kim, M. S., Jo, H. J., Shin, C. M., et al. (2013). Effect of Helicobacter pylori Eradication on Functional Dyspepsia. J. Neurogastroenterol Motil. 19 (2), 233-243. doi:10.5056/jnm.2013.19.2.233

Kim, Y. J., Chung, W. C., Kim, B. W., Kim, S. S., Kim, J. I., Kim, N. J., et al. (2017). Is Helicobacter pylori Associated Functional Dyspepsia Correlated with Dysbiosis? J. Neurogastroenterol Motil. 23 (4), 504-516. doi:10.5056/ jnm17066

Klooker, T. K., Braak, B., Koopman, K. E., Welting, O., Wouters, M. M., van der Heide, S., et al. (2010). The Mast Cell Stabiliser Ketotifen Decreases Visceral Hypersensitivity and Improves Intestinal Symptoms in Patients with Irritable Bowel Syndrome. Gut 59 (9), 1213-1221. doi:10.1136/gut.2010.213108

Koga, Y., Ohtsu, T., Kimura, K., and Asami, Y. (2019). Probiotic L. Gasseri Strain (LG21) for the Upper Gastrointestinal Tract Acting through Improvement of Indigenous Microbiota. BMJ Open Gastroenterol. 6 (1), e000314. doi:10.1136/ bmjgast-2019-000314

Kuo, B., Barnes, C. N., Nguyen, D. D., Shaywitz, D., Grimaldi, M., Renzulli, C., et al. (2021). Velusetrag Accelerates Gastric Emptying in Subjects with Gastroparesis: a Multicentre, Double-Blind, Randomised, PlaceboControlled, Phase 2 Study. Aliment. Pharmacol. Ther. 53 (10), 1090-1097. doi:10.1111/apt.16344

Lee, J. Y., Kim, N., Choi, Y. J., Park, J. H., Ashktorab, H., Smoot, D. T., et al. (2020). Expression of Tight Junction Proteins According to Functional Dyspepsia Subtype and Sex. J. Neurogastroenterol Motil. 26 (2), 248-258. doi:10.5056/ jnm19208

Malamood, M., Roberts, A., Kataria, R., Parkman, H. P., and Schey, R. (2017). Mirtazapine for Symptom Control in Refractory Gastroparesis. Drug Des. Devel Ther. 11, 1035-1041. doi:10.2147/DDDT.S125743

Malfertheiner, P., MOssner, J., Fischbach, W., Layer, P., Leodolter, A., Stolte, M., et al. (2003). Helicobacter pylori Eradication Is Beneficial in the Treatment of Functional Dyspepsia. Aliment. Pharmacol. Ther. 18 (6), 615-625. doi:10.1046/ j.1365-2036.2003.01695.x

Malinen, E., Rinttilä, T., Kajander, K., Mättö, J., Kassinen, A., Krogius, L., et al. (2005). Analysis of the Fecal Microbiota of Irritable Bowel Syndrome Patients and Healthy Controls with Real-Time PCR. Am. J. Gastroenterol. 100 (2), 373-382. doi:10.1111/j.1572-0241.2005.40312.x

Marella, H. K., Saleem, N., and Olden, K. (2019). Mirtazapine for Refractory Gastroparesis. ACG Case Rep. J. 6 (10), e00256. doi:10.14309/ cri. 0000000000000256

Markham, A. (2020). Oliceridine: First Approval. Drugs 80 (16), 1739-1744. doi:10.1007/s40265-020-01414-9

Mars, R. A. T., Yang, Y., Ward, T., Houtti, M., Priya, S., Lekatz, H. R., et al. (2020). Longitudinal Multi-Omics Reveals Subset-specific Mechanisms Underlying Irritable Bowel Syndrome. Cell 182 (6), 1460-e17. e1417. doi:10.1016/ j.cell.2020.08.007

Martínez, C., Rodiño-Janeiro, B. K., Lobo, B., Stanifer, M. L., Klaus, B., Granzow, M., et al. (2017). miR-16 and miR-125b Are Involved in Barrier Function Dysregulation through the Modulation of Claudin-2 and Cingulin Expression in the Jejunum in IBS with Diarrhoea. Gut 66 (9), 1537-1538. doi:10.1136/ gutjnl-2016-311477 
Masuy, I., Tack, J., Verbeke, K., and Carbone, F. (2019a). Acotiamide Affects Antral Motility, but Has No Effect on Fundic Motility, Gastric Emptying or Symptom Perception in Healthy Participants. Neurogastroenterol Motil. 31 (4), e13540. doi:10.1111/nmo.13540

Masuy, I., Van Oudenhove, L., and Tack, J. (2019b). Review Article: Treatment Options for Functional Dyspepsia. Aliment. Pharmacol. Ther. 49 (9), 1134-1172. doi:10.1111/apt.15191

Matricon, J., Meleine, M., Gelot, A., Piche, T., Dapoigny, M., Muller, E., et al. (2012). Review Article: Associations between Immune Activation, Intestinal Permeability and the Irritable Bowel Syndrome. Aliment. Pharmacol. Ther. 36 (11-12), 1009-1031. doi:10.1111/apt.12080

Matsueda, K., Hongo, M., Tack, J., Saito, Y., and Kato, H. (2012). A PlaceboControlled Trial of Acotiamide for Meal-Related Symptoms of Functional Dyspepsia. Gut 61 (6), 821-828. doi:10.1136/gutjnl-2011-301454

Mazzoleni, L. E., Sander, G. B., Francesconi, C. F., Mazzoleni, F., Uchoa, D. M., De Bona, L. R., et al. (2011). Helicobacter pylori Eradication in Functional Dyspepsia: HEROES Trial. Arch. Intern. Med. 171 (21), 1929-1936. doi:10.1001/archinternmed.2011.533

Mazzone, A., Strege, P. R., Gibbons, S. J., Alcaino, C., Joshi, V., Haak, A. J., et al. (2020). microRNA Overexpression in Slow Transit Constipation Leads to Reduced NaV1.5 Current and Altered Smooth Muscle Contractility. Gut 69 (5), 868-876. doi:10.1136/gutjnl-2019-318747

McColl, K., Murray, L., El-Omar, E., Dickson, A., El-Nujumi, A., Wirz, A., et al. (1998). Symptomatic Benefit from Eradicating Helicobacter pylori Infection in Patients with Nonulcer Dyspepsia. N. Engl. J. Med. 339 (26), 1869-1874. doi:10.1056/NEJM199812243392601

Mertz, H., Fass, R., Kodner, A., Yan-Go, F., Fullerton, S., and Mayer, E. A. (1998). Effect of Amitriptyline on Symptoms, Sleep, and Visceral Perception in Patients with Functional Dyspepsia. Am. J. Gastroenterol. 93 (2), 160-165. doi:10.1111/ j.1572-0241.1998.00160.x

Miwa, H., Hirai, S., Nagahara, A., Murai, T., Nishira, T., Kikuchi, S., et al. (2000). Cure of Helicobacter pylori Infection Does Not Improve Symptoms in Nonulcer Dyspepsia Patients-A Double-Blind Placebo-Controlled Study. Aliment. Pharmacol. Ther. 14 (3), 317-324. doi:10.1046/j.1365-2036.2000.00706.x

Miwa, H., Nagahara, A., Tominaga, K., Yokoyama, T., Sawada, Y., Inoue, K., et al. (2009). Efficacy of the 5-HT1A Agonist Tandospirone Citrate in Improving Symptoms of Patients with Functional Dyspepsia: a Randomized Controlled Trial. Am. J. Gastroenterol. 104 (11), 2779-2787. doi:10.1038/ajg.2009.427

Moayyedi, P., Delaney, B. C., Vakil, N., Forman, D., and Talley, N. J. (2004). The Efficacy of Proton Pump Inhibitors in Nonulcer Dyspepsia: a Systematic Review and Economic Analysis. Gastroenterology 127 (5), 1329-1337. doi:10.1053/ j.gastro.2004.08.026

Morgan, V., Pickens, D., Gautam, S., Kessler, R., and Mertz, H. (2005). Amitriptyline Reduces Rectal Pain Related Activation of the Anterior Cingulate Cortex in Patients with Irritable Bowel Syndrome. Gut 54 (5), 601-607. doi:10.1136/gut.2004.047423

Motta, J. P., Wallace, J. L., Buret, A. G., Deraison, C., and Vergnolle, N. (2021). Gastrointestinal Biofilms in Health and Disease. Nat. Rev. Gastroenterol. Hepatol. 18 (5), 314-334. doi:10.1038/s41575-020-00397-y

Muller, P. A., Koscsó, B., Rajani, G. M., Stevanovic, K., Berres, M. L., Hashimoto, D., et al. (2014). Crosstalk between Muscularis Macrophages and Enteric Neurons Regulates Gastrointestinal Motility. Cell 158 (2), 300-313. doi:10.1016/j.cell.2014.04.050

Naz, F., Malik, S., Afzal, S., and Anwar, S. A. (2013). Frequency of Seropositivity of Helicobacter pylori in Patients Presenting with Dyspepsia. J. Ayub Med. Coll. Abbottabad 25 (3-4), 50-54.

Needham, B. D., Kaddurah-Daouk, R., and Mazmanian, S. K. (2020). Gut Microbial Molecules in Behavioural and Neurodegenerative Conditions. Nat. Rev. Neurosci. 21 (12), 717-731. doi:10.1038/s41583-020-00381-0

Pannemans, J., and Tack, J. (2018). How Effective Are Secretagogues for Irritable Bowel Syndrome with Constipation. Gastroenterology 155 (6), 1677-1679. doi:10.1053/j.gastro.2018.11.005

Parkman, H. P., Yates, K., Hasler, W. L., Nguyen, L., Pasricha, P. J., Snape, W. J., et al. (2011). Clinical Features of Idiopathic Gastroparesis Vary with Sex, Body Mass, Symptom Onset, Delay in Gastric Emptying, and Gastroparesis Severity. Gastroenterology 140 (1), 101-115. doi:10.1053/j.gastro.2010.10.015

Pasricha, P. J., Grover, M., Yates, K. P., Abell, T. L., Bernard, C. E., Koch, K. L., et al. (2021). Functional Dyspepsia and Gastroparesis in Tertiary Care Are
Interchangeable Syndromes with Common Clinical and Pathologic Features. Gastroenterology 160 (6), 2006-2017. doi:10.1053/j.gastro.2021.01.230

Patterson, D., Abell, T., Rothstein, R., Koch, K., and Barnett, J. (1999). A DoubleBlind Multicenter Comparison of Domperidone and Metoclopramide in the Treatment of Diabetic Patients with Symptoms of Gastroparesis. Am. J. Gastroenterol. 94 (5), 1230-1234. doi:10.1111/j.1572-0241.1999.00456.x

Pimentel, M., Chatterjee, S., Chow, E. J., Park, S., and Kong, Y. (2006). Neomycin Improves Constipation-Predominant Irritable Bowel Syndrome in a Fashion that Is Dependent on the Presence of Methane Gas: Subanalysis of a DoubleBlind Randomized Controlled Study. Dig. Dis. Sci. 51 (8), 1297-1301. doi:10.1007/s10620-006-9104-6

Pimentel, M., Lembo, A., Chey, W. D., Zakko, S., Ringel, Y., Yu, J., et al. (2011). Rifaximin Therapy for Patients with Irritable Bowel Syndrome without Constipation. N. Engl. J. Med. 364 (1), 22-32. doi:10.1056/NEJMoa1004409

Poitras, P., Riberdy Poitras, M., Plourde, V., Boivin, M., and Verrier, P. (2002). Evolution of Visceral Sensitivity in Patients with Irritable Bowel Syndrome. Dig. Dis. Sci. 47 (4), 914-920. doi:10.1023/a:1014729125428

Pulipati, P., Sarkar, P., Jakkampudi, A., Kaila, V., Sarkar, S., Unnisa, M., et al. (2020). The Indian Gut Microbiota-Is it Unique? Indian J. Gastroenterol. 39 (2), 133-140. doi:10.1007/s12664-020-01037-8

Quigley, E. M. M. (2017). Microbiota-Brain-Gut Axis and Neurodegenerative Diseases. Curr. Neurol. Neurosci. Rep. 17 (12), 94. doi:10.1007/s11910-0170802-6

Raehal, K. M., Schmid, C. L., Groer, C. E., and Bohn, L. M. (2011). Functional Selectivity at the $\mu$-opioid Receptor: Implications for Understanding Opioid Analgesia and Tolerance. Pharmacol. Rev. 63 (4), 1001-1019. doi:10.1124/ pr.111.004598

Rahimi, R., Nikfar, S., Rezaie, A., and Abdollahi, M. (2009). Efficacy of Tricyclic Antidepressants in Irritable Bowel Syndrome: a Meta-Analysis. World J. Gastroenterol. 15 (13), 1548-1553. doi:10.3748/wjg.15.1548

Rahman, M. M., Ghoshal, U. C., Kibria, M. G., Sultana, N., Yusuf, M. A., Nahar, S., et al. (2021). Functional Dyspepsia, Peptic Ulcer, and Helicobacter pylori Infection in a Rural Community of South Asia: An Endoscopy-Assisted Household Survey. Clin. Transl Gastroenterol. 12 (4), e00334. doi:10.14309/ ctg.0000000000000334

Rao, A. S., and Camilleri, M. (2010). Review Article: Metoclopramide and Tardive Dyskinesia. Aliment. Pharmacol. Ther. 31 (1), 11-19. doi:10.1111/j.13652036.2009.04189.x

Rao, S., Lembo, A. J., Shiff, S. J., Lavins, B. J., Currie, M. G., Jia, X. D., et al. (2012). A 12-week, Randomized, Controlled Trial with a 4-week Randomized Withdrawal Period to Evaluate the Efficacy and Safety of Linaclotide in Irritable Bowel Syndrome with Constipation. Am. J. Gastroenterol. 107 (11), 1714-1725. doi:10.1038/ajg.2012.255

Reigstad, C. S., Salmonson, C. E., Rainey, J. F., 3rd, Szurszewski, J. H., Linden, D. R., Sonnenburg, J. L., et al. (2015). Gut Microbes Promote Colonic Serotonin Production through an Effect of Short-Chain Fatty Acids on Enterochromaffin Cells. FASEB J. 29 (4), 1395-1403. doi:10.1096/fj.14-259598

Rhee, S. H., Pothoulakis, C., and Mayer, E. A. (2009). Principles and Clinical Implications of the Brain-Gut-Enteric Microbiota axis. Nat. Rev. Gastroenterol. Hepatol. 6 (5), 306-314. doi:10.1038/nrgastro.2009.35

Rokkas, T., Ekmektzoglou, K., and Niv, Y. (2021). Comparative Effectiveness of 5hydroxytryptamine 3 Receptor Antagonists in Irritable Bowel Syndrome: a Network Meta-Analysis of Randomized Controlled Studies. Ann. Gastroenterol. 34 (4), 535-546. doi:10.20524/aog.2021.0619

Sanders, K. M., Koh, S. D., Ro, S., and Ward, S. M. (2012). Regulation of Gastrointestinal Motility-Iinsights from Smooth Muscle Biology. Nat. Rev. Gastroenterol. Hepatol. 9 (11), 633-645. doi:10.1038/nrgastro.2012.168

Schroeder, B. O., and Bäckhed, F. (2016). Signals from the Gut Microbiota to Distant Organs in Physiology and Disease. Nat. Med. 22 (10), 1079-1089. doi: $10.1038 / \mathrm{nm} .4185$

Sekirov, I., Russell, S. L., Antunes, L. C., and Finlay, B. B. (2010). Gut Microbiota in Health and Disease. Physiol. Rev. 90 (3), 859-904. doi:10.1152/ physrev.00045.2009

Shah, E. D., Lacy, B. E., Chey, W. D., Chang, L., and Brenner, D. M. (2021). Tegaserod for Irritable Bowel Syndrome with Constipation in Women Younger Than 65 Years without Cardiovascular Disease: Pooled Analyses of 4 Controlled Trials. Am. J. Gastroenterol. 116 (8), 1601-1611. doi:10.14309/ ajg.0000000000001313 
Shanahan, F., Ghosh, T. S., and O’Toole, P. W. (2021). The Healthy MicrobiomeWhat Is the Definition of a Healthy Gut Microbiome? Gastroenterology 160 (2), 483-494. doi:10.1053/j.gastro.2020.09.057

Sharma, A., Rao, S. S. C., Kearns, K., Orleck, K. D., and Waldman, S. A. (2021). Review Article: Diagnosis, Management and Patient Perspectives of the Spectrum of Constipation Disorders. Aliment. Pharmacol. Ther. 53 (12), 1250-1267. doi:10.1111/apt.16369

Shin, A., Preidis, G. A., Shulman, R., and Kashyap, P. C. (2019). The Gut Microbiome in Adult and Pediatric Functional Gastrointestinal Disorders. Clin. Gastroenterol. Hepatol. 17 (2), 256-274. doi:10.1016/j.cgh.2018.08.054

Shukla, R., Ghoshal, U., Dhole, T. N., and Ghoshal, U. C. (2015). Fecal Microbiota in Patients with Irritable Bowel Syndrome Compared with Healthy Controls Using Real-Time Polymerase Chain Reaction: An Evidence of Dysbiosis. Dig. Dis. Sci. 60 (10), 2953-2962. doi:10.1007/s10620-015-3607-y

Simrén, M., and Tack, J. (2018). New Treatments and Therapeutic Targets for IBS and Other Functional Bowel Disorders. Nat. Rev. Gastroenterol. Hepatol. 15 (10), 589-605. doi:10.1038/s41575-018-0034-5

Singh, R., Ghoshal, U. C., Kumar, S., and Mittal, B. (2017). Genetic Variants of Immune-Related Genes IL17F and IL10 Are Associated with Functional Dyspepsia: A Case-Control Study. Indian J. Gastroenterol. 36 (5), 343-352. doi:10.1007/s12664-017-0788-7

Singh, R., Ha, S. E., Wei, L., Jin, B., Zogg, H., Poudrier, S. M., et al. (2021a). miR10b-5p Rescues Diabetes and Gastrointestinal Dysmotility. Gastroenterology 160 (5), 1662-e18. e1618. doi:10.1053/j.gastro.2020.12.062

Singh, R., Mittal, B., and Ghoshal, U. C. (2016). Functional Dyspepsia Is Associated with GN 33 C825T and CCK-AR T/C Polymorphism. Eur. J. Gastroenterol. Hepatol. 28 (2), 226-232. doi:10.1097/MEG.0000000000000511

Singh, R., Wei, L., and Ghoshal, U. C. (2021b). Micro-organic Basis of Functional Gastrointestinal (GI) Disorders: Role of microRNAs in GI Pacemaking Cells. Indian J. Gastroenterol. 40 (2), 102-110. doi:10.1007/s12664-021-01159-7

Singh, R., Zogg, H., and Ro, S. (2021c). Role of microRNAs in Disorders of GutBrain Interactions: Clinical Insights and Therapeutic Alternatives. Jpm 11 (10), 1021. doi:10.3390/jpm11101021

Singh, R., Zogg, H., Wei, L., Bartlett, A., Ghoshal, U. C., Rajender, S., et al. (2021d). Gut Microbial Dysbiosis in the Pathogenesis of Gastrointestinal Dysmotility and Metabolic Disorders. J. Neurogastroenterol Motil. 27 (1), 19-34. doi:10.5056/jnm20149

Singla, N. K., Skobieranda, F., Soergel, D. G., Salamea, M., Burt, D. A., Demitrack, M. A., et al. (2019). APOLLO-2: A Randomized, Placebo and Active-Controlled Phase III Study Investigating Oliceridine (TRV130), a G Protein-Biased Ligand at the $\mu$-Opioid Receptor, for Management of Moderate to Severe Acute Pain Following Abdominoplasty. Pain Pract. 19 (7), 715-731. doi:10.1111/ papr.12801

Spencer, N. J., and Hu, H. (2020). Enteric Nervous System: Sensory Transduction, Neural Circuits and Gastrointestinal Motility. Nat. Rev. Gastroenterol. Hepatol. 17 (6), 338-351. doi:10.1038/s41575-020-0271-2

Sperber, A. D., Bangdiwala, S. I., Drossman, D. A., Ghoshal, U. C., Simren, M., Tack, J., et al. (2021a). Worldwide Prevalence and Burden of Functional Gastrointestinal Disorders, Results of Rome Foundation Global Study. Gastroenterology 160 (1), 99-e3. e113. doi:10.1053/j.gastro.2020.04.014

Sperber, A. D., Freud, T., Aziz, I., Palsson, O. S., Drossman, D. A., Dumitrascu, D. L., et al. (2021b). Greater Overlap of Rome IV Disorders of Gut-Brain Interactions Leads to Increased Disease Severity and Poorer Quality of Life. Clin. Gastroenterol. Hepatol. S1542-3565 (21), 00580-00582. doi:10.1016/ j.cgh.2021.05.042

Sternini, C., Anselmi, L., and Rozengurt, E. (2008). Enteroendocrine Cells: a Site of 'taste' in Gastrointestinal Chemosensing. Curr. Opin. Endocrinol. Diabetes Obes. 15 (1), 73-78. doi:10.1097/MED.0b013e3282f43a73

Sun, Q., Jia, Q., Song, L., and Duan, L. (2019). Alterations in Fecal Short-Chain Fatty Acids in Patients with Irritable Bowel Syndrome: A Systematic Review and Meta-Analysis. Medicine (Baltimore) 98 (7), e14513. doi:10.1097/ MD.0000000000014513

Suzuki, H., and Moayyedi, P. (2013). Helicobacter pylori Infection in Functional Dyspepsia. Nat. Rev. Gastroenterol. Hepatol. 10 (3), 168-174. doi:10.1038/ nrgastro.2013.9

Suzuki, H. (2017). The Application of the Rome IV Criteria to Functional Esophagogastroduodenal Disorders in Asia. J. Neurogastroenterol Motil. 23 (3), 325-333. doi:10.5056/jnm17018
Tack, J., Janssen, P., Masaoka, T., Farré, R., and Van Oudenhove, L. (2012). Efficacy of Buspirone, a Fundus-Relaxing Drug, in Patients with Functional Dyspepsia. Clin. Gastroenterol. Hepatol. 10 (11), 1239-1245. doi:10.1016/j.cgh.2012.06.036

Tack, J., Ly, H. G., Carbone, F., Vanheel, H., Vanuytsel, T., Holvoet, L., et al. (2016) Efficacy of Mirtazapine in Patients with Functional Dyspepsia and Weight Loss. Clin. Gastroenterol. Hepatol. 14 (3), 385-e4. doi:10.1016/j.cgh.2015.09.043

Talley, N. J., and Ford, A. C. (2015). Functional Dyspepsia. N. Engl. J. Med. 373 (19), 1853-1863. doi:10.1056/NEJMra1501505

Talley, N. J., Janssens, J., Lauritsen, K., Rácz, I., and Bolling-Sternevald, E. (1999a). Eradication of Helicobacter pylori in Functional Dyspepsia: Randomised Double Blind Placebo Controlled Trial with 12 Months' Follow up. The Optimal Regimen Cures Helicobacter Induced Dyspepsia (ORCHID) Study Group. BMJ 318 (7187), 833-837. doi:10.1136/bmj.318.7187.833

Talley, N. J., Vakil, N., Ballard, E. D., Fennerty, M. B., and Fennerty, M. B. (1999b). Absence of Benefit of Eradicating Helicobacter pylori in Patients with Nonulcer Dyspepsia. N. Engl. J. Med. 341 (15), 1106-1111. doi:10.1056/ NEJM199910073411502

Tan, V. P., Liu, K. S., Lam, F. Y., Hung, I. F., Yuen, M. F., and Leung, W. K. (2017). Randomised Clinical Trial: Rifaximin versus Placebo for the Treatment of Functional Dyspepsia. Aliment. Pharmacol. Ther. 45 (6), 767-776. doi:10.1111/ apt.13945

Thoua, N. M., Murray, C. D., Winchester, W. J., Roy, A. J., Pitcher, M. C., Kamm, M. A., et al. (2009). Amitriptyline Modifies the Visceral Hypersensitivity Response to Acute Stress in the Irritable Bowel Syndrome. Aliment. Pharmacol. Ther. 29 (5), 552-560. doi:10.1111/j.1365-2036.2008.03918.x

Törnblom, H., and Drossman, D. A. (2015). Centrally Targeted Pharmacotherapy for Chronic Abdominal Pain. Neurogastroenterol Motil. 27 (4), 455-467. doi:10.1111/nmo.12509

Törnblom, H., and Drossman, D. A. (2018). Psychotropics, Antidepressants, and Visceral Analgesics in Functional Gastrointestinal Disorders. Curr. Gastroenterol. Rep. 20 (12), 58. doi:10.1007/s11894-018-0664-3

Turcotte, J. F., Kao, D., Mah, S. J., Claggett, B., Saltzman, J. R., Fedorak, R. N., et al. (2013). Breaks in the wall: Increased Gaps in the Intestinal Epithelium of Irritable Bowel Syndrome Patients Identified by Confocal Laser Endomicroscopy (With Videos). Gastrointest. Endosc. 77 (4), 624-630. doi:10.1016/j.gie.2012.11.006

Van Oudenhove, L., Crowell, M. D., Drossman, D. A., Halpert, A. D., Keefer, L., Lackner, J. M., et al. (2016). Biopsychosocial Aspects of Functional Gastrointestinal Disorders. Gastroenterology S0016-5085 (16), 1355-1367. doi:10.1053/j.gastro.2016.02.027

Veldhuyzen van Zanten, S., Fedorak, R. N., Lambert, J., Cohen, L., and Vanjaka, A. (2003). Absence of Symptomatic Benefit of Lansoprazole, Clarithromycin, and Amoxicillin Triple Therapy in Eradication of Helicobacter pylori Positive, Functional (Nonulcer) Dyspepsia. Am. J. Gastroenterol. 98 (9), 1963-1969. doi:10.1111/j.1572-0241.2003.07583.x

Vijayvargiya, P., Busciglio, I., Burton, D., Donato, L., Lueke, A., and Camilleri, M. (2018). Bile Acid Deficiency in a Subgroup of Patients with Irritable Bowel Syndrome with Constipation Based on Biomarkers in Serum and Fecal Samples. Clin. Gastroenterol. Hepatol. 16 (4), 522-527. doi:10.1016/j.cgh.2017.06.039

Vijayvargiya, P., and Camilleri, M. (2019). Current Practice in the Diagnosis of Bile Acid Diarrhea. Gastroenterology 156 (5), 1233-1238. doi:10.1053/j.gastro.2018.11.069

Walters, J. R., Johnston, I. M., Nolan, J. D., Vassie, C., Pruzanski, M. E., and Shapiro, D. A. (2015). The Response of Patients with Bile Acid Diarrhoea to the Farnesoid X Receptor Agonist Obeticholic Acid. Aliment. Pharmacol. Ther. 41 (1), 54-64. doi:10.1111/apt.12999

Wauters, L., Ceulemans, M., Frings, D., Lambaerts, M., Accarie, A., Toth, J., et al. (2021). Proton Pump Inhibitors Reduce Duodenal Eosinophilia, Mast Cells, and Permeability in Patients with Functional Dyspepsia. Gastroenterology 160 (5), 1521-e9. doi:10.1053/j.gastro.2020.12.016

Wei, L., Singh, R., Ha, S. E., Martin, A. M., Jones, L. A., Jin, B., et al. (2021a). Serotonin Deficiency Is Associated with Delayed Gastric Emptying. Gastroenterology 160 (7), 2451-e19. doi:10.1053/j.gastro.2021.02.060

Wei, L., Singh, R., Ro, S., and Ghoshal, U. C. (2021b). Gut Microbiota Dysbiosis in Functional Gastrointestinal Disorders: Underpinning the Symptoms and Pathophysiology. JGH Open 5 (9), 976-987. doi:10.1002/jgh3.12528

Williams, B. B., Van Benschoten, A. H., Cimermancic, P., Donia, M. S., Zimmermann, M., Taketani, M., et al. (2014). Discovery and Characterization of Gut Microbiota 
Decarboxylases that Can Produce the Neurotransmitter Tryptamine. Cell Host Microbe 16 (4), 495-503. doi:10.1016/j.chom.2014.09.001

Wouters, M. M., Balemans, D., Van Wanrooy, S., Dooley, J., Cibert-Goton, V., Alpizar, Y. A., et al. (2016a). Histamine Receptor H1-Mediated Sensitization of TRPV1 Mediates Visceral Hypersensitivity and Symptoms in Patients with Irritable Bowel Syndrome. Gastroenterology 150 (4), 875-e9. doi:10.1053/j.gastro.2015.12.034

Wouters, M. M., Vicario, M., and Santos, J. (2016b). The Role of Mast Cells in Functional GI Disorders. Gut 65 (1), 155-168. doi:10.1136/gutjnl-2015-309151

Yoo, B. B., and Mazmanian, S. K. (2017). The Enteric Network: Interactions between the Immune and Nervous Systems of the Gut. Immunity 46 (6), 910-926. doi:10.1016/j.immuni.2017.05.011

Zhao, W., Zhong, X., Zhuang, X., Ji, H., Li, X., Li, A., et al. (2013). Evaluation of Helicobacter pylori Eradication and Drug Therapy in Patients with Functional Dyspepsia. Exp. Ther. Med. 6 (1), 37-44. doi:10.3892/etm.2013.1109

Zheng, H., Liu, Y. J., Chen, Z. C., and Fan, G. Q. (2021). miR-222 Regulates Cell Growth, Apoptosis, and Autophagy of Interstitial Cells of Cajal Isolated from Slow Transit Constipation Rats by Targeting C-Kit. Indian J. Gastroenterol. 40 (2), 198-208. doi:10.1007/s12664-020-01143-7

Zikos, T. A., Kamal, A. N., Neshatian, L., Triadafilopoulos, G., Clarke, J. O., Nandwani, M., et al. (2019). High Prevalence of Slow Transit Constipation in
Patients with Gastroparesis. J. Neurogastroenterol Motil. 25 (2), 267-275. doi:10.5056/jnm18206

Conflict of Interest: The authors declare that the research was conducted in the absence of any commercial or financial relationships that could be construed as a potential conflict of interest.

Publisher's Note: All claims expressed in this article are solely those of the authors and do not necessarily represent those of their affiliated organizations, or those of the publisher, the editors and the reviewers. Any product that may be evaluated in this article, or claim that may be made by its manufacturer, is not guaranteed or endorsed by the publisher.

Copyright $\odot 2022$ Singh, Zogg, Ghoshal and Ro. This is an open-access article distributed under the terms of the Creative Commons Attribution License (CC BY). The use, distribution or reproduction in other forums is permitted, provided the original author(s) and the copyright owner(s) are credited and that the original publication in this journal is cited, in accordance with accepted academic practice. No use, distribution or reproduction is permitted which does not comply with these terms. 